Open Access

\title{
Actor's social complexity: a proposal for managing the iStar model
}

\author{
Fábio Penha ${ }^{1 *}$ (D) Erica Miranda², Márcia Lucena ${ }^{2}$, Leonardo Lucena ${ }^{1}$, Fernanda Alencar ${ }^{3}$ and Celso Sá Filho ${ }^{3}$
}

\author{
*Correspondence: \\ fabio.penha@ifrn.edu.br \\ ${ }^{1}$ Federal Institute of Education, \\ Science and Technology of Rio \\ Grande do Norte (IFRN), 59015-300 \\ Natal, Brazil \\ Full list of author information is \\ available at the end of the article
}

\begin{abstract}
Complex systems are inherent to modern society, in which individuals, organizations, and computational elements relate with each other to achieve a predefined purpose, which transcends individual goals. In this context, these systems' complexity is originated by the large number of parts interacting in a non-simple way, given the properties of these parts and the laws, as well as by the wishes that govern these interactions. Also, in organizations, there is a need for additional information to understand this universe considering the already consolidated static and dynamic dimensions. With this purpose, the iStar framework was developed to capture and represent intentional and social information in two views: Strategic Dependency (SD) and Strategic Rationale (SR). This framework, however, does not offer alternatives to deal with the complexity that is inherent to modern society systems, which is related to a large number of parts interacting, when modeled from their views. The problem is present in monolithic languages because they do not consist of building blocks, such as subprocesses or modules. Despite this problem, the iStar framework provides modeling versatility by combining goal-oriented paradigms and agents. Another positive point is the focus on intentional and social properties, thus providing expressiveness aligned with the modern society's demand, in which everything is related. Therefore, the objective of this research was to provide ways for the iStar framework to deal with the complexity presented by complex systems and, consequently, make iStar models understandable to be used, in a given context. The proposal is based on a state of the art review to create an interdependente part for the iStar models and will make the construction of views as a composition of these parts possible. To make it happen, and considering its benefits, a textual notation (SMiLe - Scalable Modular iStar Language) was conceived and applied to support the architecture within this social modeling scenario. The proposal and its artifacts were submitted to a proof of concept, and then, through adjustments, an evaluation was carried by the users through a case study. The results pointed to evidence of the possible management of iStar model and an improvement in the understanding of this model, suggesting that the proposed solution is a feasible alternative for the established objective.
\end{abstract}

Keywords: iStar framework, Interdependent part, Textual notation, Views composition

\section{Introduction}

Computational systems strengthen their relationship with society with each challenge faced, thus assuming a strategic position in the most several activities and areas (Yu 2009). With the increasing relevance of intelligent devices in organizations and humanity's daily life, the intensity of this relationship is presented on a scale and level that has no precedent

(c) The Author(s). 2018 Open Access This article is distributed under the terms of the Creative Commons Attribution 4.0 International License (http://creativecommons.org/licenses/by/4.0/), which permits unrestricted use, distribution, and reproduction in any medium, provided you give appropriate credit to the original author(s) and the source, provide a link to the Creative Commons license, and indicate if changes were made. 
(Gubbi et al. 2013). This scale can be inferred by the following statements and projections (Gubbi et al. 2013; Bello and Zeadally 2013): (a) In 2011, the number of devices in the world exceeded the number of people; (b) In the year 2013, there were already nine billion devices in the world; (c) By 2020, there's a projection of 50 billion devices in the world, all of them interconnected and interacting among themselves to offer society comfort and information.

The awareness of this sociotechnical environment, in which different devices and their information influence the most distinct activities, has provided even more complex systems. Complex systems are defined as a combination of a large number of parts that interact in a non-simple way given their properties and the laws ruling these interactions (Reijers and Mendling 2008; Langlois 2002). This complexity, along with the tendency that these parts have to grow unprecedently in scale and level, makes the modeling process an activity that is even more critical to comprehend and, consequently, software aligned with the organization's goals (Barjis 2008).

Despite the community's efforts to provide approaches and techniques to deal with this large number of parts (devices and individuals) that relate with each other to form a whole (organization), the rate of failed projects continues to grow (Barjis 2008). When discussing the activities associated with the software development process, one encounters difficulty in understanding and modeling these parts, especially when it involves a large number of parties driven by a higher purpose. In this scenario, requirements engineers are responsible for presenting solutions to problems that, for the most part, are incredibly complex to understand due to the lack of clarity about the system's responsibilities (Sommerville 2010).

In addition to this scenario in which systems are getting even more complex with time, the organizations are worried about their strategic alignment, which allows the optimization of the people's contribution, thus resulting in the reduction of efforts and resources dedicated to non-intentional goals. This way, to better contemplate the organizations' universe of information and their strategic alignment, the modeling has to be able to capture more than structures and behaviors, aiming to demonstrate influences and motivations of the problem studied (Yu 1996). Thus, the iStar framework emerges to abstract and capture the analyzed environment's intentional and social information. This representation is formulated in two views: Strategic Dependency (SD) and Strategic Rationale (SR). The iStar framework, through its model, offers a goal and agent-oriented approach and has been used in several situations, such as telecommunications, air traffic control, agriculture and health (Yu 2009).

However, considering what is exposed in Alencar et al. (2008); Esquivel (2008); Franch (2010); Alencar et al. (2010); Franch (2012); Lima et al. (2016) and the reports of the use of the iStar framework in (Esquivel 2008; Annosi et al. 2008; Carvallo and Franch 2009), it is possible to note that interdependent parts are absent in the definition of the iStar model. This absence inhibits the possibility of managing the complexity of complex systems (Parnas 1972; Baldwin and Clark 2006). Therefore, there is a resistance from the industry, evidenced by the experiences of use reported in Esquivel (2008); Annosi et al. (2008); Carvallo and Franch (2009), which reinforces the language's lack of modularity and, as a consequence, scalability of graphics models. Due to the relevance of this problem, some efforts have already been made by the iStar community, such as the integration between aspects concepts and iStar model (Alencar et al. 2008; Alencar et al. 2010); an 
extension of the iStar framework to the service-oriented approach (Esquivel 2008); and the development of model using modules (Franch 2010).

The proposed approach makes it possible to manage the complex systems' reading by making the construction of diagrams (views) flexible through the composition of parts of the model (domain). This way, the views can be grouped into smaller scenarios, analyzed, read and understood according to a specific situation in a bigger context, meeting a particular need of the stakeholders. Considering the information presented above, and aiming at managing the iStar models' representations without overloading the framework with new concepts (e.g., aspects and services), this approach proposes an interdependente part conceived from the iStar framework's concepts (intentional elements, actors, and relationships). To not bring up any conflict with the concepts presented in the framework, the term "actor's social complexity", found in the iStar Wiki, absorbs this social unity (interdependente part) that will make up the social modeling (whole). This part was designed for an incremental construction of the concepts and elements of the SD and SR views.

Some works served as a base for the conception and instrumentalization of this proposal, such as Esquivel's work (Esquivel 2008), which presented an intermediate model which will contain information for the model's conception; Franch's work (Franch 2010), which showed a minimalist worry, using, in his proposal, already-existing concepts; and, lastly, the separation of the model and its possible views (SD, SR or both), found in Dalpiaz et al's work (Dalpiaz et al. 2016). This proposal's contribution lays on the understanding of a comprehensive and interdependent conceptual unity which can be incrementally built by the framework's elements/concepts and in a textual notation developed to favor the human comprehension within the Dual Coding Theory (Paivio 1991).

Therefore, the objective of this work was to offer an alternative to managing the complexity of views through the creation of interdependent parts with well-defined inputs and outputs. The absence of interdependent parts in the iStar model inhibits the possibility of managing the complexity of complex systems (Parnas 1972; Baldwin and Clark 2006). In addition to making complexity manageable by being able to transform a large monolithic structure into a smaller set of blocks, modularity may offer other benefits such as (Parnas 1972; Baldwin and Clark 2006): enabling parallel work by dividing it into interdependent blocks; and accommodating future uncertainties using encapsulated structures, thus ensuring that a change is not propagated.

This work is structured as follows: in Section 2, "Background", the literature review is presented in order for the actor's social complexity to be later defined within this research as the modeling unity suggested for the iStar framework's social modeling, which is done in Section 3. The proposal's instrumentalization from three levels of layer abstraction is demonstrated in Section 4. The work also presents Section 5, "Proposal assessment and results", which contemplates the validation of the developed proposal and Section 6, "Discussions", in which considerations related to the theme are made. Section 7 discussed the related works, emphasizing the contributions of this research. Finally, in Section 8, "Conclusion", the final considerations were presented.

\section{Background}

This section aims to offer the central concepts and theories involved in this work. However, only the indicative of the most relevant references were presented. Thus, this section 
was structured as follows: (i) concepts and limitations of the iStar framework; concluding with (ii) the related works presented.

\section{1 iStar framework and limitations}

The iStar framework introduces aspects of social modeling and Strategic Rationale into methods used in information system engineering, especially when it comes to the requirements level (Yu 2009). The framework's approach has brought up incentives, which has encouraged the production of many works in recent years, such as Franch (2012): an approach that relates the goal-oriented and agent paradigms and brings attention to the environment's intentional properties, as well as their relationships, instead of immediate behaviors. This author states that these incentives provide a rich expressiveness, which is appropriate for the world's social concepts.

The iStar model combines a notation of intentions distributed within the organization (Yu 1996): (a) the Strategic Dependency (SD) model, which describes the dependency relationships between the organization's actors elements; and (b) the Strategic Rationale (SR) model, used to describe the motivations for the actor element to choose one or the other specific configuration to meet a demand. Through these models, it is possible to shape, analyze and reconfigure the relationships between elements, emphasizing their intentions, responsibilities, and vulnerabilities.

\subsection{Strategic dependency model - SD}

The SD model provides an intentional description of organizational functioning regarding a network of dependency between actors, whether they are human or not. This model captures and provides the intentional structure of flows and activities that are evident in the processes. The intentional structure obtained in this model is defined by an actor (depender), which relates to another actor (dependee) through an intentional element (dependum). The intuitive meaning of dependence described in the intentional structure is that the (depender), which depends on another actor (dependee) to meet a demand (dependum), can accomplish a goal or purpose that it would not be able to achieve otherwise (Yu 1996).

In this model, there are four types of dependency relationships, which are specified by the following intentional elements: goal, task, resource, and softgoal. Each intentional element represents a contract in which it will indicate the depender's vulnerability. Figure 1 shows the types of dependency relationships proposed by the framework that can be captured through the model. Figure 2, in its turn, shows a complete picture of the healthcare.

\subsection{Strategic rationale model - SR}

While the SD model describes the external relations between actors (depender and dependee) through the dependum, the Strategic Rationale (SR) model describes the actors' possibilities to meet a given demand. When expanding an actor from an iStar modeling, the framework's intentional elements associate with each other with the goal of presenting the possible configurations, which may meet a demand. The main types of associations between intentional elements are (i) means-end and (ii)task-decomposition (Yu 1996).

Figure 3 shows a fragment of an SR model, in which the Claims Manager actor is evidenced. In this fragment, the possible configurations specific to the actor are 


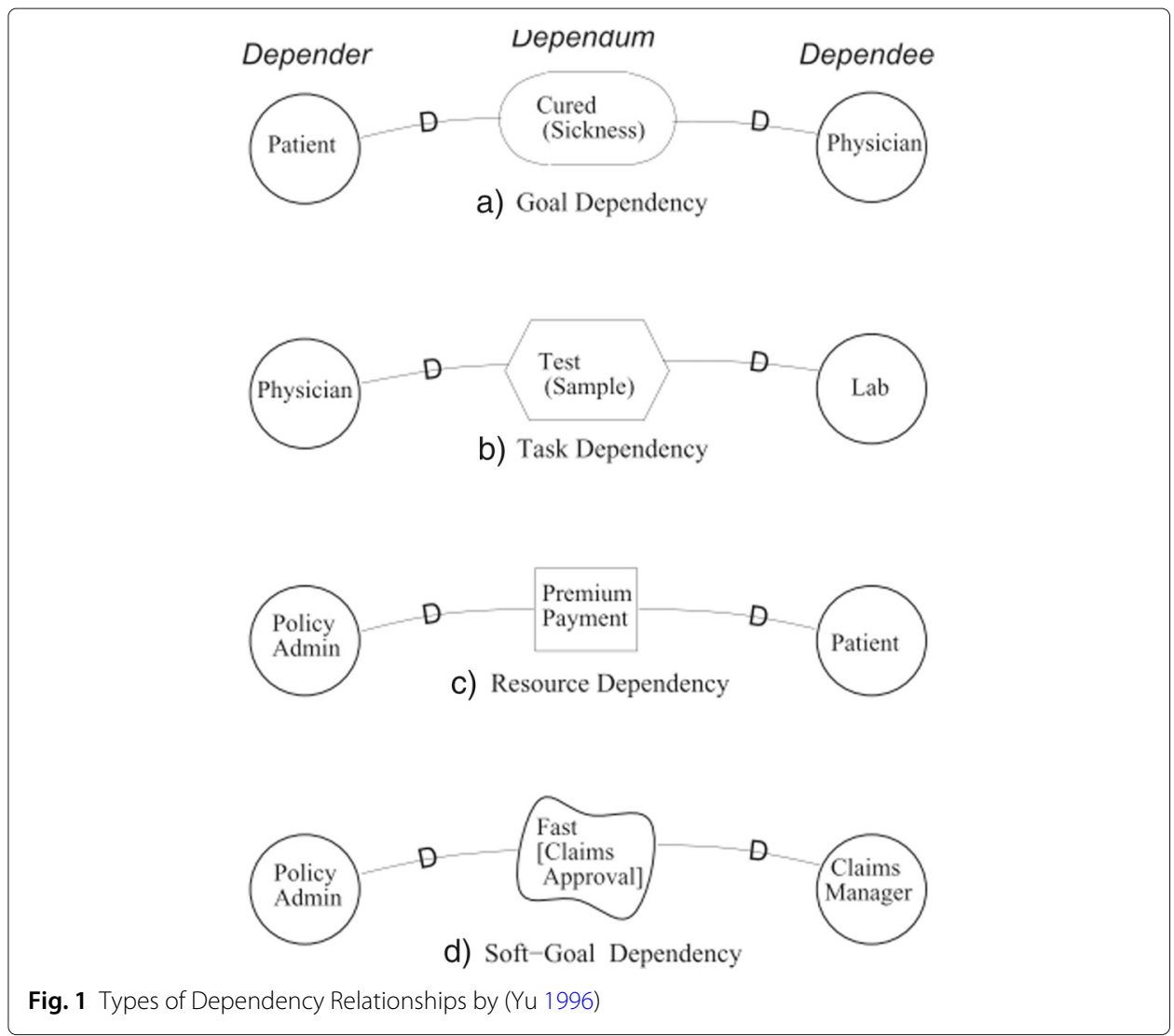

demonstrated, such as: (i) how the Claims Manager intends to attend the physician's need; and (ii) alternatives to existing configurations, which can be performed to achieve the evaluated treatment target better.

\subsection{1 iStar framework limitations}

Despite the great academic relevance of the iStar framework, the iStar community already classifies some of the iStar framework's features as limitations (Esquivel 2008; Franch

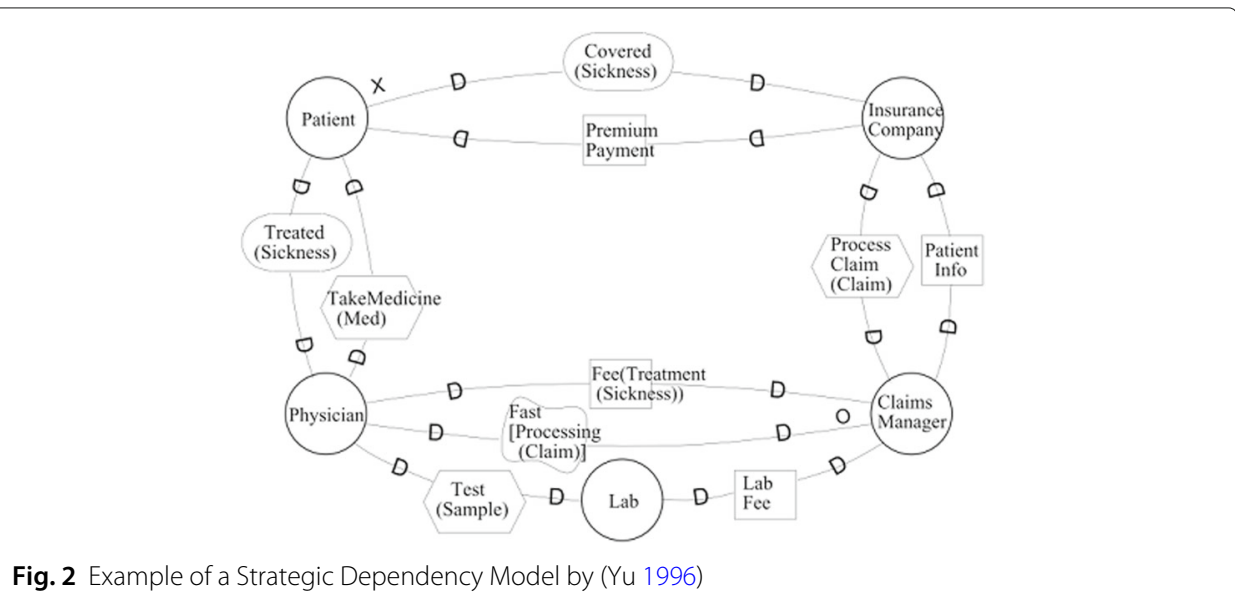




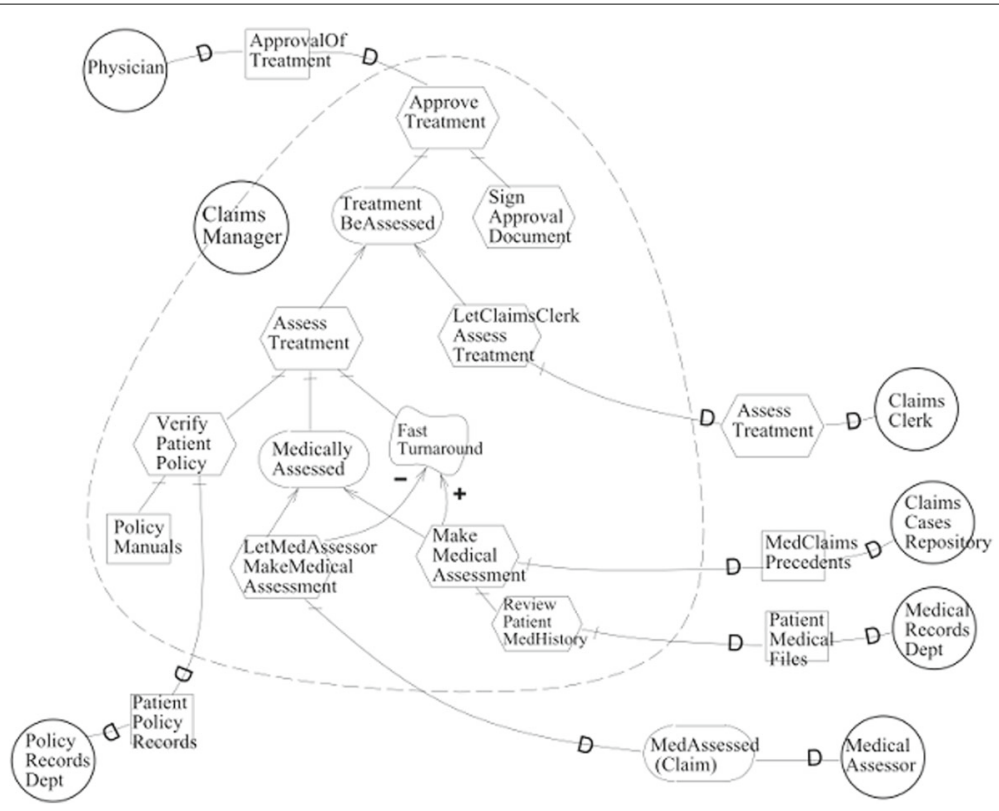

Fig. 3 Example of a Strategic Rationale Model fragment by (Yu 1996)

2012; Lima et al. 2016; Annosi et al. 2008; Carvallo and Franch 2009). These studies considered, as an example, that iStar does not respond, in its entirety, to the modularity, reusability, and scalability characteristics. Among the features that were not considered and that are seen as weaknesses, (Alencar et al. 2008; Esquivel 2008; Franch 2010)'s works highlight the issue of the model's modularity as being of greater damage to the framework, due to the correlation to reuse and scalability as a consequence of modularity. In the framework's conception, Eric Yu, in Yu (1996), already showed some apprehension regarding scalability when he mentioned the need to perform tests in real and complex domains.

This lack of modularity is evidenced through the iStar model's monolithic representation strategy, in which all the elements of an organization, which includes the elements in the SD and SR models, are represented in a single block, without considering any specific situation (Esquivel 2008). The difficulty of reading this monolithic strategy becomes more evident when applied to systems, which involve an enormous amount of elements, as seen in Fig. 4. In such systems, the organization is more than the simple sum of the parts, at least in the pragmatic sense that, given the properties of the parts and the laws for their interaction, it is not common to infer the properties of the whole thing. Although the iStar framework has a short number of elements and relationships, there are still types and rules that direct the construction of the whole.

The modularity feature can be defined as the ability of the modeling language to provide well-defined building blocks for model development. Building blocks should allow the encapsulation of the model's internal structures into a real modeling application. This features guarantees that changes in one part of the model will not be propagated to other parts (Esquivel 2008), considering that modeling with building blocks is directly related to the concept of modularity and scalability. Researchers face this challenge, as well as propose alternatives (Alencar et al. 2008; Esquivel 2008; Franch 2010; 2012; Alencar et 


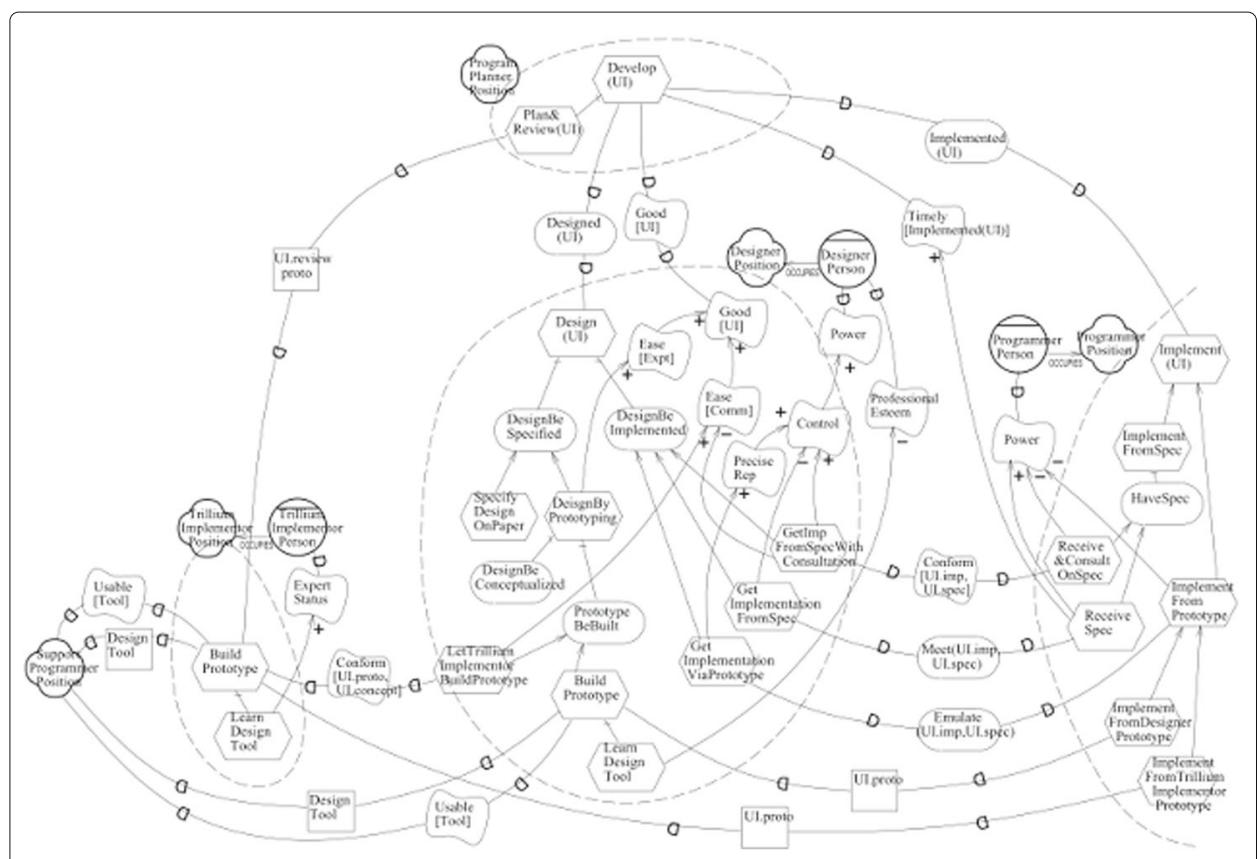

Fig. 4 Example of the Monolithic Structure of the Strategic Rationale Model by (Yu 1996)

al. 2010). Of the difficulties mentioned, the work of Esquivel (2008) places the modularity issue as the most important and confirms this assertion by presenting reuse and scalability as consequences of modularity. This can be a solution to modularity and bring positive impacts to reuse and scalability.

In many domains, modularity is essential to deal with the increasing complexity of products and systems through the decomposition into smaller parts that can be independently managed, but that function as a whole (Reijers and Mendling 2008; Genon et al. 2011). The concept of modularity has drawn attention from engineers, corporate strategists, and industry and academic researchers. This notoriety occurs due to the benefits that are expected to be brought by modularization which, from the engineering point of view, generally has three purposes (Parnas 1972; Baldwin and Clark 2006): (i) make complexity manageable; (ii) enable parallel works; and (iii) accommodate future uncertainties. These benefits generated by the decomposition of the whole into manageable parts will only be valid if this partition is precise, complete and unambiguous (Baldwin and Clark 2003).

When it comes to the iStar framework, despite having works that address this problem, obtaining a scalable model is still a challenge (Yu 1996). The solutions proposed so far have not been widely accepted by the community or do not sufficiently embrace all instances of the iStar. Lima et al. (2016)'s study performed a mapping of studies that approach the framework's scalability. Based on Lima et al. (2016), the following five characteristics that enrich the definition of scalability for iStar were compiled: (i) the possibility of manipulating several actors in an analysis without impacting the modeling; (ii) treating and manipulating diferente-size applications the same way; (iii) incorporating new resources without significant impacts; (iv) having views at varying levels of abstraction; (v) being easily modifiable. 


\subsection{Alternatives found in the literature for the limitations found}

Considering this explanation, there are works (Alencar et al. 2008; Alencar et al. 2010; Annosi et al. 2008; Carvallo and Franch 2009; Nunes 2009; Lucena et al. 2011) that present benefits related to the iStar framework's modularity. However, this proposal prioritized works associated with the possibility of fragmenting the iStar model into interdependent parts, such as i) Esquivel's work (Esquivel 2008) about a service-oriented method for the iStar framework; ii) Franch's work (Franch 2010) about a definition of modules for the iStar framework.

Esquivel's proposal (Esquivel 2008) carries an empirical evaluation deeply performed in the iStar framework. The author identified that the framework model had a limitation due to the lack of modular mechanisms to build iStar models. Due to the absence of this characteristic, models such as SR represent a monolithic view in which all the elements of an organization are represented in the same level of abstraction. Figure 5a presents this model in the organizational structure's monolithic view, and alongside it, the global model proposed to improve the framework's modeling process. One of the crucial points of this approach is the use of the intermediary model, which is used to mediate the organizational information and the development of other models, where each carries a specific purpose. This can be seen in Fig. $5 \mathrm{~b}$.

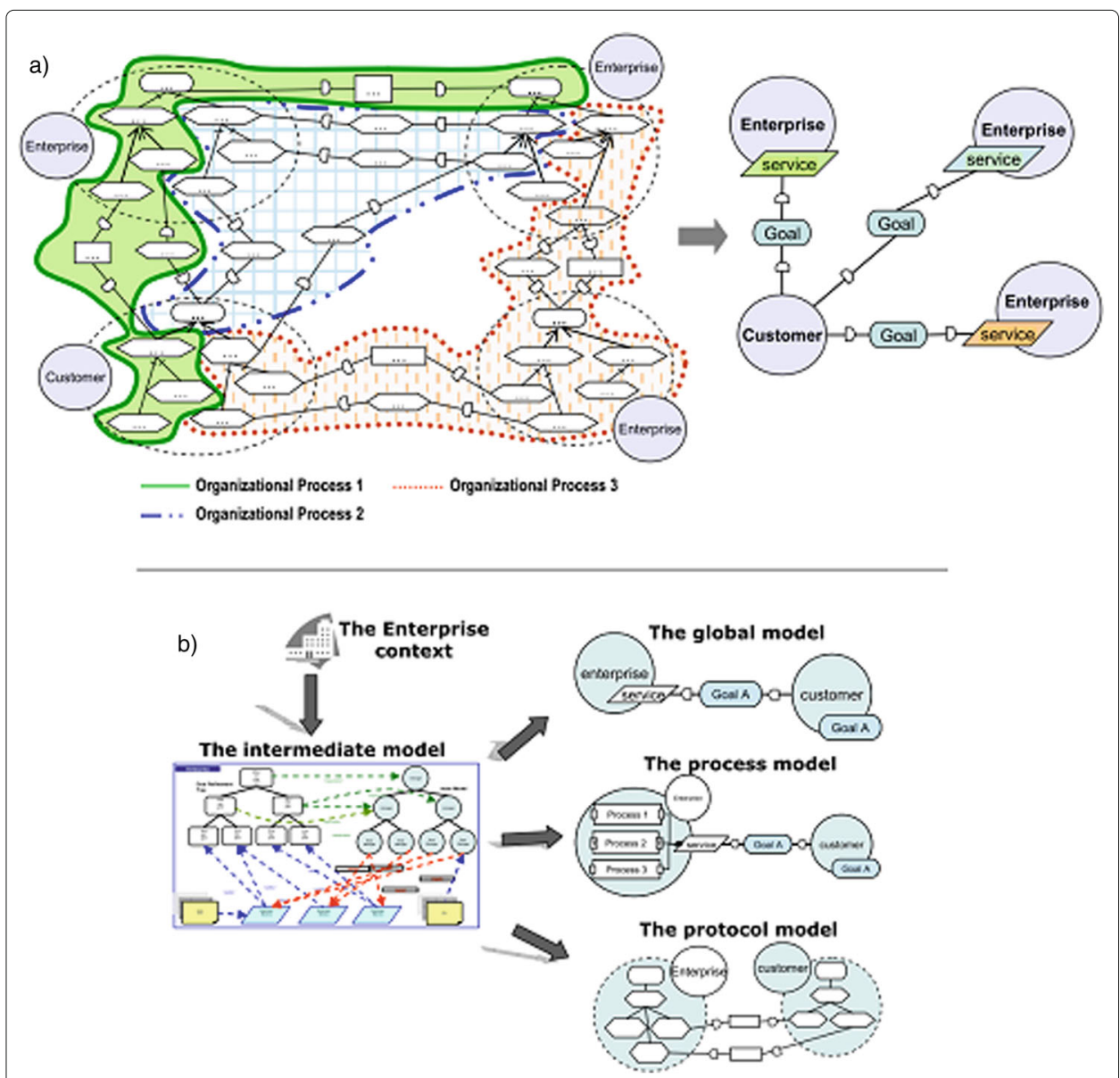

Fig. 5 Service proposal approach by (Esquivel 2008). a SR model for the global service model. b Intermediate model for the proposed models 
In another proposal, Xavier Franch (Franch 2010) presented the definition of five modules to represent small models significant to the iStar language. These five modules are specializations from two other important modules: the SR Module and the SD Module. The SR Module is specialized into three different types of modules, which are: the Task-decomposition Module, for all new elements refined from task along with their relationships; the Means-end SR Module (Fig. 6b), for all new elements refined from the goal and their relationships; and the Contribution Module (Fig. 6), which includes all intentional elements that contribute to the softgoal. Two examples of these modules can be seen in Fig. 6. For methodological reasons, the module proposal also brings two particular types for the SD Module: the Actor Diagram SD Module, which contains actors and relationships; and the Dependency SD Modules, which comprises an interesting dependency relationship between two actors through an intentional element.

\section{Actor's social complexity}

The definition of the Actor's social Complexity, being it understood as the interdependent part of social modeling, is the primary goal of this proposal. This interdependente part can be orchestrated with other parts to represent the iStar models, in line with the version defined in iStarWiki (I*Wiki). It is important to emphasize that this actor's perspective (interdependent part of social modeling) can be understood as a view. This view comprises all the elements related to the actor element, such as all the association relationships; all the dependency relations, whether the actor is the depender or the dependee; and, finally, all its internal elements. By having this interdependent part of the social modeling defined, it is possible to achieve graphic representations composed of a set of perspectives from different actors.

These compositions will be represented by views, which will contain graphical information such as position, size, width, and shape, representing elements of iStar models. From this moment, the term "actor's social complexity" represents an interdependent part that is part of Social Modeling. Considering some of the concepts and works already discussed, it is necessary to relate this term with the following concepts: the building block (Esquivel 2008), and module (Franch 2010). In this definition of the elements that make up the actor's social complexity, the external relationships are composed of the desired actor, the external intentional elemento and the other actor in the relationship. These relationships are always presented, regardless of the role assumed (depender or dependee) by the actor in it.

To delimit the actor's social complexity, the concept of perspective was used to maximize the understanding of a graphical abstraction through the hybrid approach (SD and

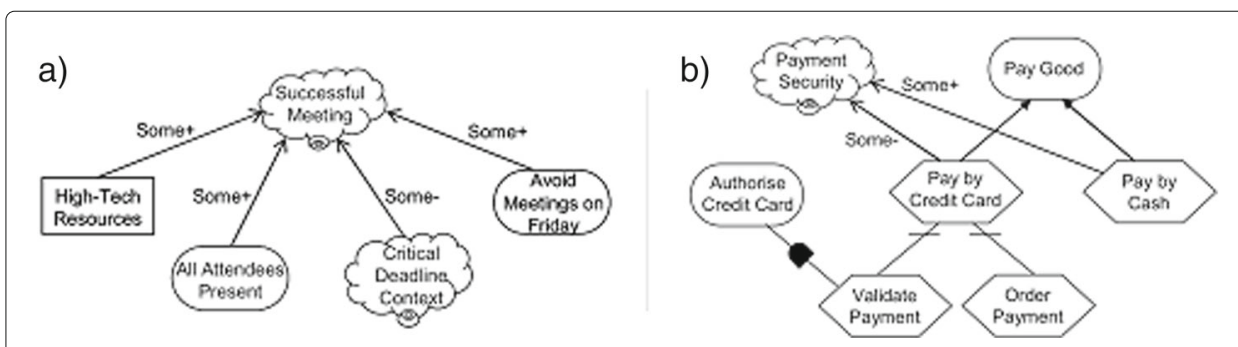

Fig. 6 Examples of SR model modules by (Franch 2010). a Contribution module.. b Means-End module 
SR) of the models. Considering the modularity, the viewpoint mechanism offers high cohesion and low coupling, which is because this mechanism comprises a grouping of several elements, presenting them under a specific subdomain (Cavalcanti 2015). Eric Yu, in his critical analysis of the framework (Yu 2011), mentioned the need for an understanding of perspectives in social modeling, since it indicated that the iStar framework should have as many SR models as there were actors in the modeling. The actor's social complexity is aligned with the mentioned need, with a specificity of this proposal, since the actor's social construction is a hybrid approach of the elements presented in SD and SR. To illustrate these concepts within a social modeling, Fig. 7 shows a scenario with the relationships and intentions between nine actors (Patient, Insurance Plan, Physician, Director, Orthopedist, Cardiologist, Resource Allocator, Medical Board and Eduardo) with skills needed to meet a specific demand.

In this proposal's conception, Fig. 8 exemplifies, in an SR view, two of the nine of the actor's social complexities presented: patient's social complexity (see Fig. 8a) and the physician's social complexity (see Fig. 8b). With the definition of the actor's social complexity, the graphical complexity can be managed, considering both the exhibition and the omission of elements, through the combinations of these definitions. This representation of a social modeling composed of two social complexities is shown in Fig. 9.

The elaboration of the definitions of the actor's social complexities included in the social modeling can be carried out in an incremental process in which only the meaning of existence itself is mandatory. Thus, the definitions of the name and type of actor must be performed when creating the actor's social complexity, making it possible, at any time, for new social information (associations, dependency relationships, and internal elements) to be defined. This way, the elaboration of the actor's social complexity can permeate the definitions, which are sometimes included in the SD model and sometimes included in the SR model.

Reflecting on what was previously exposed, it is worth noting that the composition of the interdependent parts (actor's social complexity) is established based on the social

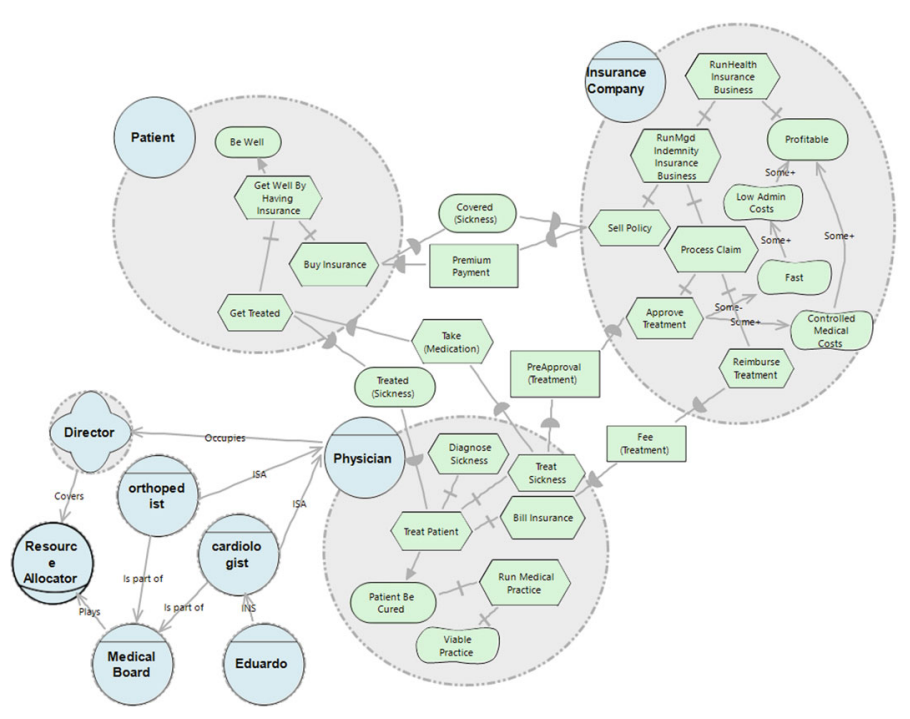

Fig. 7 View of iStar models for a Insurance Company adapted of Yu (1996) 


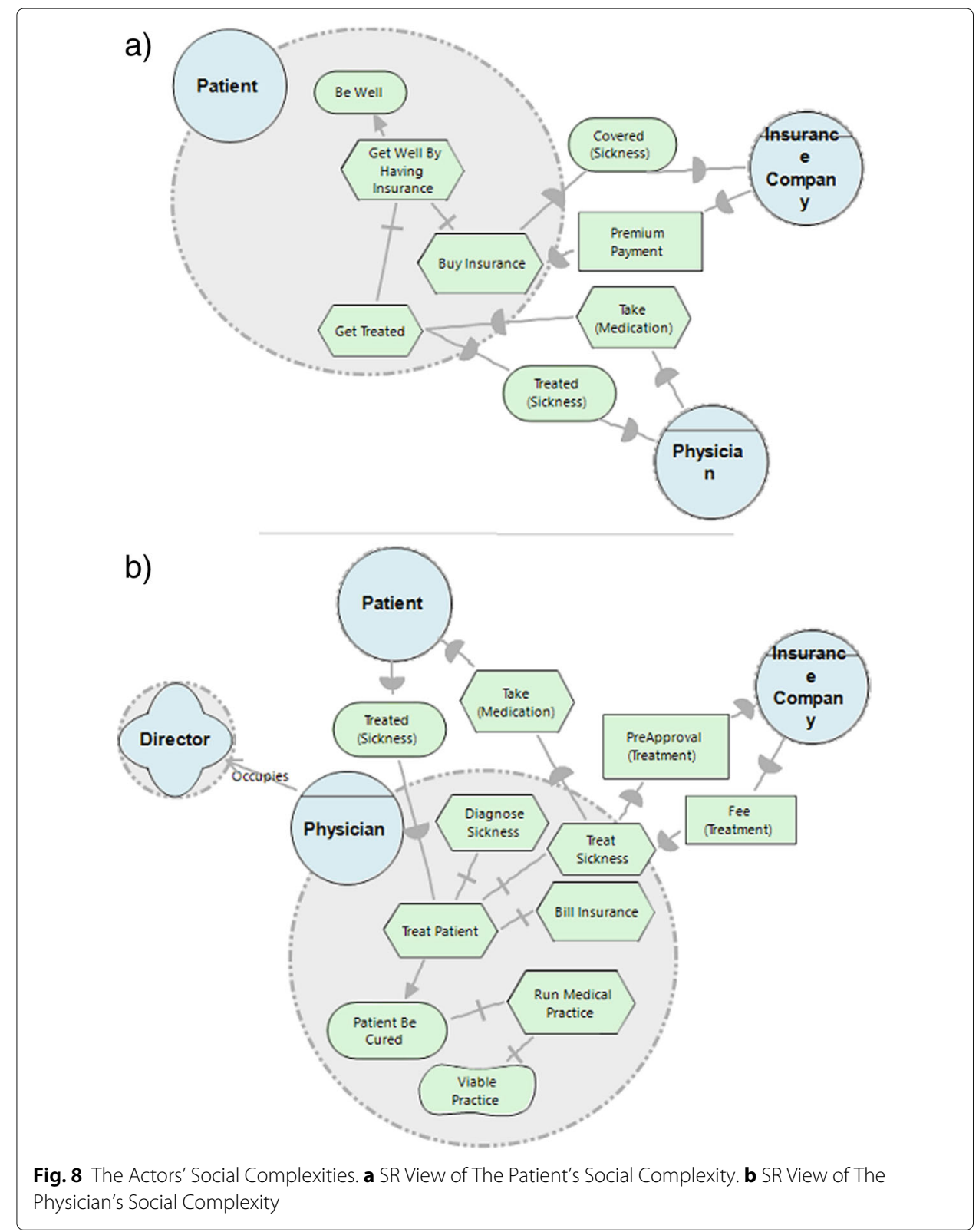

information understood in each of the actor's perspective. Thus, the composition mechanism, which will compile the information contained in the actor's social complexities, will respect the associations and relationships with other actors as a determinant factor for the very existence of the elements mentioned. As an example, it is possible to affirm that a statement of some element, which has not been defined in the social model, will come into existence because of this. For this reason, the declaration of a new element in the actor's social complexity should take into account the social model.

\section{Proposal instrumentation}

From this definition, a framework was needed to clarify the relationships required to achieve the modular structure. A conceptual model with this objective was considered, knowing that the models reflect the types of understanding sought by the professionals of 


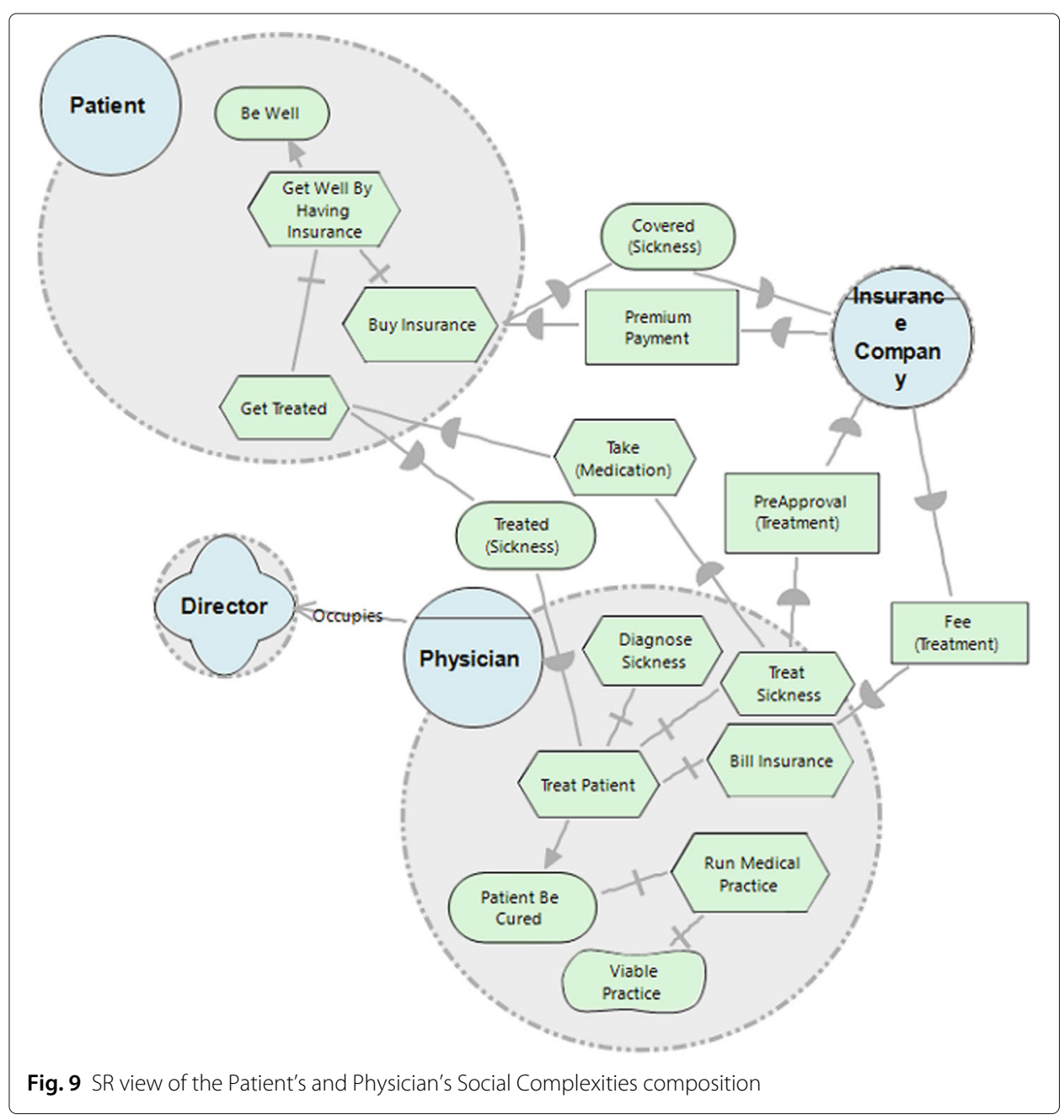

the area (Yu 2009). In the Software Engineering context, modeling is a fundamental part of the software development process. This fact is because it helps to explain the static part (data, structures and internal states) and the dynamics of the system (how the software works) (Mazanec and Macek 2012).

Considering this software modeling, the languages and textual notations do not bring innovations. However, textual language is notorious for studies that question the superiority of the graphical language, the technological advances of tools that deal directly with textual models and their benefits. As possible benefits of textual notation, one can mention greater facility in developing integration and manipulating languages (parses, generators and code translators); quality in formatting; obtaining a graphical summary from the textual input; versioning; and platform independence (Mazanec and Macek 2012; Petre 1995; Grönninger et al. 2014).

Given the above, in addition to providing a modular design for the construction of the iStar framework social model, the proposal, in its nature, aims to provide a way to separate social information from graphical information, allowing the independence between them. With this, it had the purpose of aggregating the mentioned benefits of textual notation in the framework. To understand the scope of this proposal and how the proposed 
solution can fit within the context of requirements analysis, Fig. 10 shows a vision of the intended framework. This vision demonstrates the concretization of this proposal as a whole, through layers of abstraction with different responsibilities, composed of artifacts. These layers are understood as:

Underlying the proposal, (i) the base layer provides social information through a modular textual notation, with syntactic and semantic rules based on the iStar framework. Incorporated in the definition, the notation intends to have a closer reading of what is natural for humans, but without losing the semantic formality to avoid ambiguities and allow automation. This textual notation was called SMiLe (Scalable Modular iStar Language).

(ii) The intermediate layer is composed of tools to manage the information included in the textual base. The tools are developed from the iStar settings. At present time, the idealized tools are: SMiLeCompiler - a compiler created to automate the syntactic and semantic analysis based on the grammar and the definitions of the iStar models, in addition to extracting quantitative information and performing vertical (e.g., architectural model) and horizontal (e.g. iStarML) transformations; and the SMiLeQL (SMiLe Query Language) to provide a simple language (for example, Structured Query Language) for consulting the textual base.

Finally, (iii) the top layer abstracts the complexity of the previous layer to provide a user-friendly environment for end users. The environments originated from this layer are intended to: edit and organize diagrams that represent a composition of the actors' social complexities; manipulate textual notation; represent modeling in a hybrid way (graphical and textual); present quantitative information; and allow the historical monitoring of the modeling evolution, due to the facility of integration of the textual base with some version control web service (e.g. GitHub - collaborative development platform).

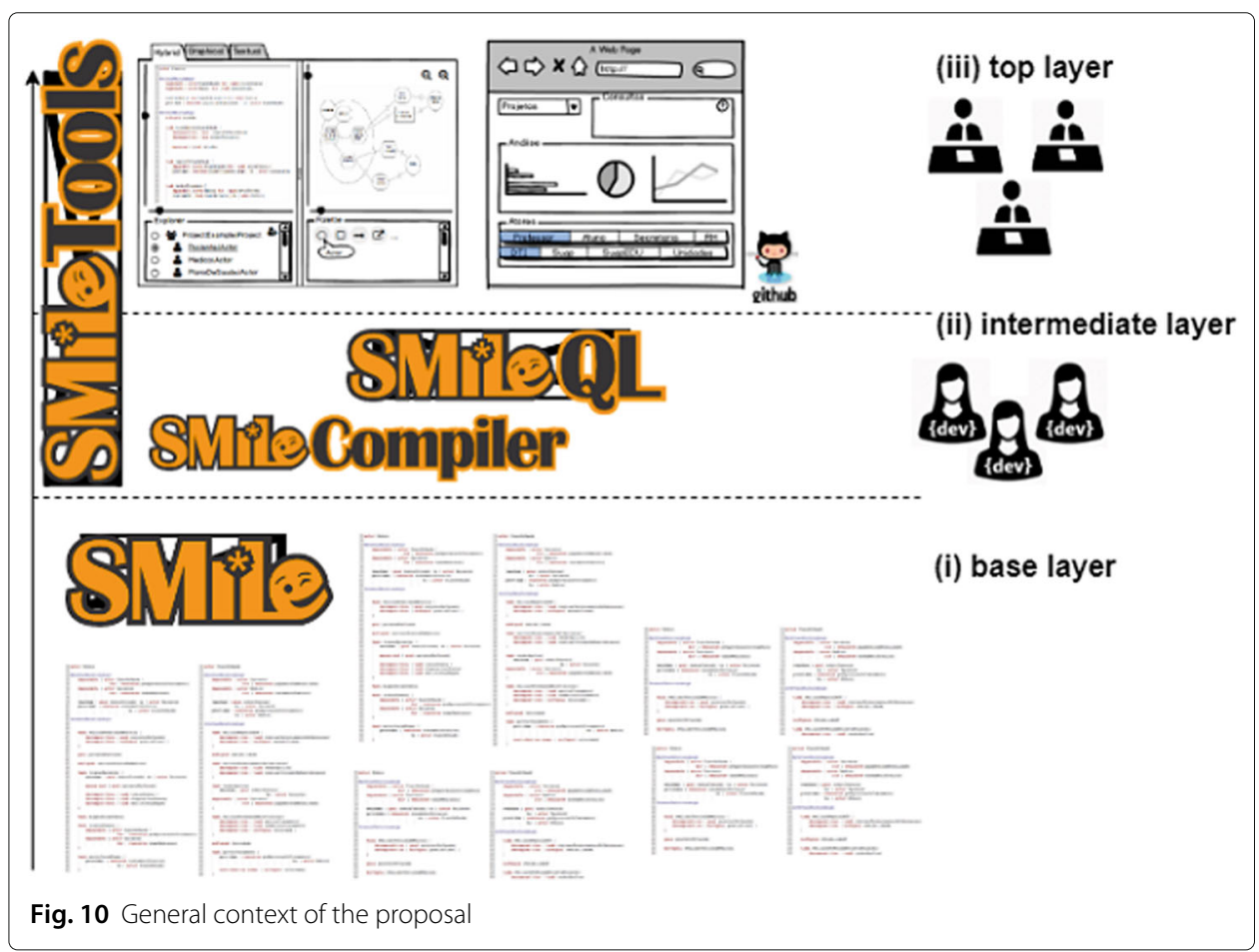


Within this vision, it is necessary to prioritize the base layer to design the textual notation (SMiLe). Following the primary requirement, which bases the social modeling through block compositions, requirements that could strengthen the primary requirement and could profit from the benefits of a textual model were designed. For this, the requirements were conceived through concepts and cognitive approaches, which evidence the functioning and limitations of human understanding (Paivio 1991; Sweller et al. 1998). In Mazanec and Macek (2012); Boucher et al. (2010); Classen et al. (2011); Abdelzad et al. (2015) the best practices for writing a textual notation were learned from the reported experiences. After presenting how these requirements were substantiated, the list of requirements that guided the elaboration of SMiLe is shown below:

- REQ1. Allow social modeling composed of interdependent parts from the monolithic structure of iStar models. To do this, these interdependent parts must be able to allow other parts that compose them to be read and understood independently without losing the information that, in social modeling, a certain part has a relation of dependence with other parts - which is called interdependence. This independent reading and understanding of other parts happen as the definitions of social modeling are fragmented in every interdependent part. With fragmentation, the iStar model can be elaborated from the composition of these interdependent, understandable, and manageable parts.

- REQ2. Expand the verbal stimulus of the framework's graphical models. In Software Engineering, it is well known that there is a hegemony of graphical modeling to represent, abstract and communicate the reality analyzed. However, there are other alternatives, each with its specificities, for modeling requirements, such as natural language, mathematical specification, and structured design language (Sommerville 2010). To foster the understanding and reading of the models, a hybrid approach (textual and graphical) is important to broaden the understanding of representations. Therefore, the reading of the modeling should be as close as possible to the natural human reading. With this reading close to natural, the ambition is to strengthen modeling understanding and learning through both representations, thus enhancing the individual abilities and experiences of each individual in a community.

- REQ3. Present a concise and readable structure for machines. While it is understandable to humans, it is expected that a device will be able to analyze and understand the pre-established structure patterns. These characteristics have the purpose of enabling controllable, automated mechanisms to grant qualitative (for example, indicating patterns of misuse for modeling) and quantitative (for example, providing accurate information about the number of times a given element is being required) analysis of the iStar modeling.

\subsection{SMiLe and the social information of the iStar framework models}

To delineate the social information of the iStar models, it was structured and formalized in a textual notation called SMiLe, conceived from the actor's social complexity. SMiLe presents an alternative for textual modeling to graphical constructions in line with Gonçalves' indication (Gonçalves et al. 2018), which determines the need to instrumentalize the conceptual proposal to guarantee its effectiveness as a solution. It is important 
to note that for Zhi and Ruhe (2013), the use of visual elements may not be enough to present all information to users and the association of an adequate amount of textual explanations can be considered a good practice to create a more comprehensible representation.

Figure 11 presents the initial definition of the SMiLe grammar, whose iStar models were composed of a set of actor's social complexity declarations in which the social information are represented textually. Each actor's social complexity contemplates, as seen in its definition, in which the actor is a central element, the elements of the iStar models on three perspectives: definition of the actor and its associations with other actors; external intentional relationship declarations; and, finally, internal intentional relationship declarations.

\subsection{SMiLe grammar}

The actor's social complexity begins with the definition of the actor and its associations with other actors. The actor's description is performed in two steps, as seen in Fig. 12. First, the actor is declared by using the type of actor and its name, which is an alphanumeric identifier that is unique in the context. There are four types of actor: the generic type, actor; and its specializations, agent, role, and position. Then, the actor's associations with other actors can be defined. Their associations are specified by type, followed by a list of actors declaration. In the textual model, these types of associations assume the following reserved words: instanceOf, isPartOf, occupies, covers, plays, and isA.

Continuing with the definition of the actor's social complexity, the next step is promoted by the external intentional relationship declarations. The external intentional relationships are expressed in the two actor's social complexities and represent both the actors in the relationship, regardless of the responsibility (depender or dependee) taken in the relationship. This occurs to bring clarity to the responsibility regarding the relationship since textual notation is sensitive to the human reading.

The SMiLe grammar classifies the external intentional relationship declaration into two types, as observed in Fig. 13, according to the responsibility taken. When the actor takes the depender's responsibility, the relationship declaration will always indicate the dependee and the target intentional element, specifying the following reasoning logic for the reader: the depender depends on the dependee to meet a specific demand. Differently, to qualify the dependee's responsibility, three types of external relationships were used: carriesOut when the intentional element is a task; provides, when the intentional element is a resource; and achieves, for goal and softgoal elements.

To complete the structure, internal intentional relationship declarations are performed with the possibility of being composed of external intentional relationships and internal relationships between the intentional elements. When defining the internal intentional relationship declarations, the relationship is classified into three types: decomposition; contribution, which is composed of some diferente types to specify the the contribution;

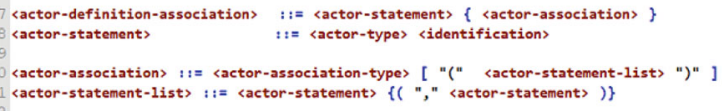

Fig. 11 Initial settings for the SMiLe Grammar 


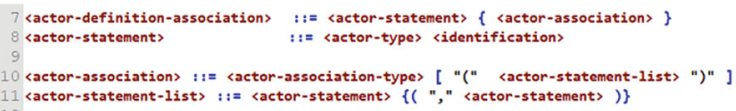

Fig. 12 Definition of the actor type and his associations

and means-end. Also, each statement may have a list of internally declared intentional elements, as seen in Fig. 14.

As an example of the SMiLe Grammar instantiation, Fig. 15 shows an actor's social complexity being represented in the SMiLe textual notation for an SR view of the social information contained in the Insurance Company actor (part of Fig. 7).

\subsection{SMiLeCompiler}

Within the tools presented in this proposal, two essential artifacts were emphasized: the modular textual notation SMiLe, because it is the base for the proposed architecture; and the SMiLeCompiler, since it guarantees the textual structures according to the syntactic and semantic rules of the iStar models and SMiLe's definitions. The last artifact, collaborating in Medeiros (2017), is evidence that the REQ3, which was to present a concise and readable structure for machines, has been achieved.

Figure 16 shows the inputs, such as the actor's social complexity set described in SMiLe, and three distinct output types: a file in the iStarML Settings to benefit from the graphical specifications and the iStar community, which already uses it as a model of interoperability between tools; a structure that contains information of the quantitative analysis with the possibility of working the models' qualitative; and a structure for storing information related to warnings and errors found during the syntactic and semantic analysis.

The tool was implemented following the SMiLe considerations, which were initially designed to satisfy the iStar framework's SD model. For this model, the SMiLeCompiler implements the following requirements: read several SMiLe files; define scope management mechanisms to avoid repeated elements; indicate inconsistency in the models defined in SMiLe; check if the element relationships make sense based on the iStar model settings, and show quantitative information to assist in model analysis.

As a proof of concept of the proposed approach and also to evaluate the impacts of the use of SMiLe, the verification and prototyping of the approach were performed. The main line of research was the search for evidence related to reducing the complexity of iStar models. The proposal addressed this problem from the modularity of the models promoted through the concept of the actor's social complexity. Thus, the goal was also to verify if this approach offers an alternative to managing the monolithic structure of iStar models.

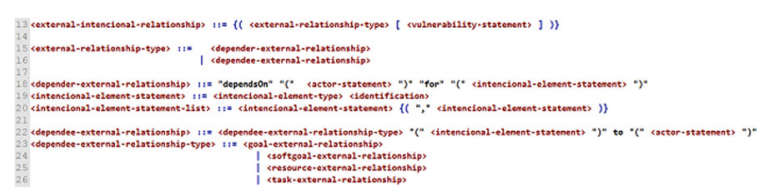

Fig. 13 Definition of the external intentional relationships 


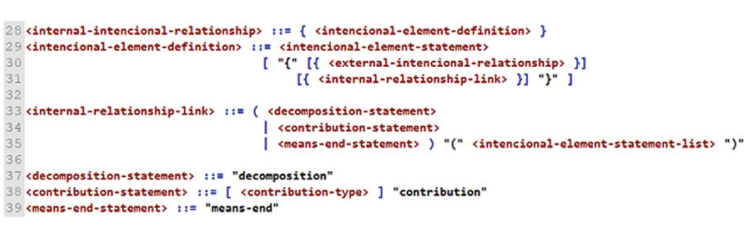

Fig. 14 Definition of the internal intentional relationships

Considering this proof of concept, the proposed instrumentation and Silva et al's work (Silva et al. 2016), it is understood that the maturation of this work involves a refinement of some points related to the visualizations extracted from the social information of the context, which is described in the actor's social complexity. For this, the following challenges listed by Silva et al. (2016) should be considered: i) the possibility of navigating between the visions generated by the compositions; ii) the implementation of mechanisms of interaction and integrity between the visions and the modeling problem; and iii) the contemplation of fundamental human-computer interaction requirements.

\section{Proposal assessment and results}

From the proof of concept, it was possible to plan and perform validation to identify the influence of the proposed approach in offering an alternative to managing the complexities of the iStar model's graphical representations. For this validation, a mixed approach was adopted, in which instruments for qualitative and quantitative researches were used (Creswell 2009). It is important to emphasize that the tests and the studies were carried out in an academic environment, although professionals from the industry were also involved. Considering this, the term "validation" will be used to refer to the evaluation performed.

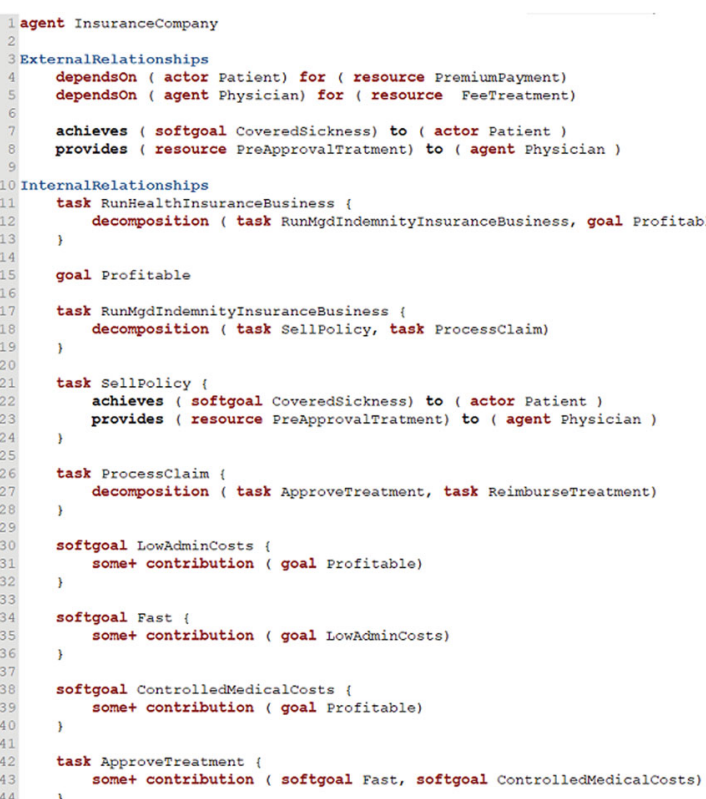

Fig. 15 SMiLe view of the Insurance Company's Social Complexity 


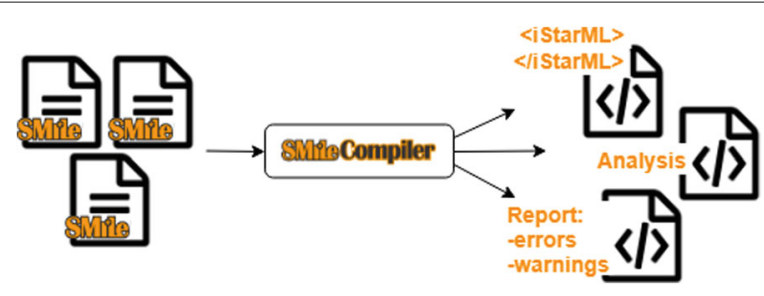

Fig. 16 SMiLeCompiler inputs and outputs

Initially, two specific research questions were developed to guide the validation process. The first research question aimed at investigating if the segmentation strategy for the iStar framework's monolithic model from the actor's social complexities would provide more manageable diagrams according to the needs of the stakeholders. Therefore, RQ1 is: would the proposed graphical construction, provided by the compositions of the actor's social complexities, allow to elaborate diagrams that could concentrate on a given situation?

The second research question, in its turn, aimed to verify the potential of the SMiLe's textual structure for offering the participants a friendly reading and how this reading would provide subsidies to help understand the iStar framework model considering a hybrid approach (graphical and textual). Thus, RQ2 is: would the SMiLe, through its structure and reserved words, help to read and understand the iStar framework model?

\subsection{Methodology}

The research was conducted to answer these questions through the correlation of the proposal, the concepts presented and the phenomenon under study to favor the recognition of probable causes. This way, the instruments used presented open questions (later classified and pre-coded) and closed questions (containing response categories or Likert scale). In the questions whose answers were proposed in the Likert scale, the intermediate or neutral answers were suppressed so that the participant could be assertive. In addition to the forms to be filled out by the participants, execution and closure scripts were prepared, as well as observation forms for the researchers.

The experimental plan for the phenomena to be studied included quasi-experimental research instruments, action research, and ethnography as described by Bryman (2006). The purpose was the triangulation of results and the search for unexpected answers. In this plan, a script including the activities to be carried out, the materials needed and the organization of the activities for both the researchers and the participants was included. The activities were distributed in two days (see Fig. 17). On the first day, participants had contact with each other through expositive and participative activities, as well as the development of theoretical and practical exercises of the iStar framework models. When planning these activities, moments dedicated to group and intergroup discussions were included, so that the moment could provide a richness of themes, applications, differences and contexts of use.

The second day began with a moment for answering the remaining doubts, followed by (i) a presentation about the research in progress and the validation proposed; (ii) a moment to gather signatures on the Term of Free and Informed Consent (TFIC) and the Term of Image, Audio and Video Use (TIAVU) by those who wished to participate in the 


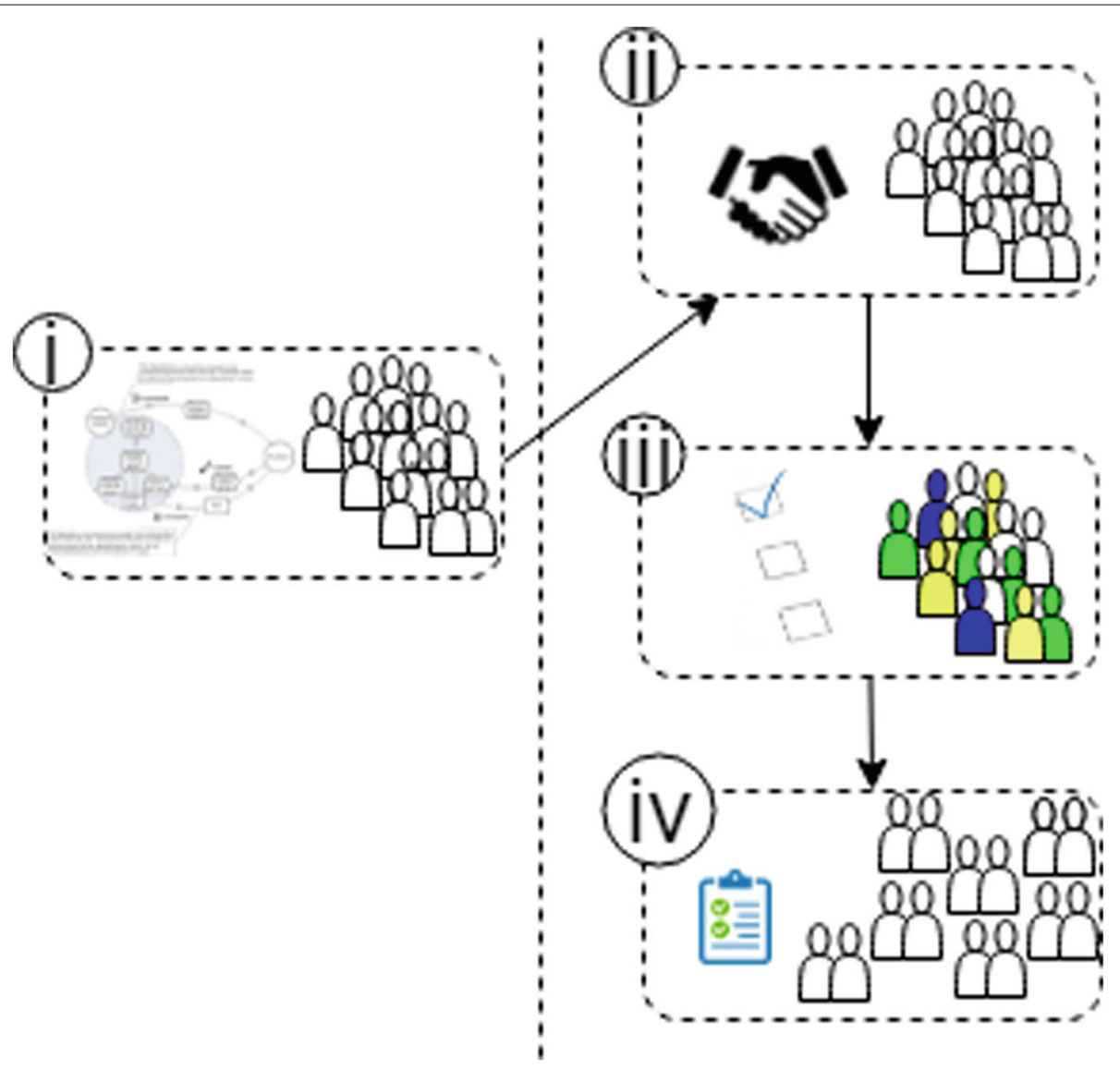

Fig. 17 Flow of the assessment activities

study; (iii) filling the demographic form and distributing the participants into pairs and assortment to define the order of execution of the proposed scenarios; (iv) filling a form with the representation of a scenario graphically modeled from the iStar framework, and filling a form with the representation of a scenario graphically modeled from the iStar framework as well as the SMiLe modular textual notation (hybrid representation).

Before the actual validation was carried out, a pilot test was performed to calibrate the instruments of two participants. One of the participants had wide expertise in the software development industry, as well as an academic master1s degree in Requirements Engineering; the other participant had experience in software development. In this occasion, the reactions and interactions of the participants with the presentations, activities, and documents used were observed by the researchers. After these planned moments, participants were interviewed using a semi-structured script. With this test, it was possible to identify some validity issues and threats (such as mortality, selection, compensation) that were corrected in time to apply the final version of the instruments to the participants.

\subsubsection{Subjects}

In the research's experimental plan, it was indicated that the interventions should be applied to two groups of students in the Software Engineering course, especially in the context of the Requirements Engineering discipline. When the plan was designed, it was decided that eighteen students would participate in the validation, but two declined, and 
another two could only be present in one of the two days planned, which automatically eliminated them from the study.

All participants were male, although initially there was a female participant. The participants' ages ranged from 19 to 30 years old. The experience of each participant with software development is quite diverse; on the other hand, except for two participants, all of the others worked in teams to develop software. The UML language was known to all participants, and one of them mentioned having basic knowledge in the iStar framework. Table 1 presents the participants' main demographic data, in which the participants were identified using the following nomenclature: $\mathrm{P}<$ participant $>+00<$ sequence number $>$.

In order to make the text simpler and agile, the pairs of participants were identified in Table 2 following the subsequent classification: $\mathrm{Pa}<$ pair $>+00<$ sequence number $>$; the identification previously defined for each participant; and the order of execution (Type 1 and Type 2) indicating the sequence of the documentation used by the pair. The Type 1 documentation aimed to collect data on the representation of the iStar models in blocks from a modeled scenario, while the Type 2 documentation characterizes, when it comes to reading and writing, the textual representation proposed and analyzes the hybrid representation from a modeled scenario and the modular concept presented.

\subsubsection{Environment and materials used}

The environment used for the interactions was the classroom of the Requirements Engineering discipline. In this location, there were conventional equipment (computers, multimedia projector, sound box) and traditional furniture (tables, chairs, whiteboard), which were arranged for lectures. After the presentation carried out on the first day, the arrangement of the furniture was flexibilized so that the groups could be more closely integrated. On the second day, adjustments were made to accommodate better the pairs defined. The materials used, such as sheets of paper and pens, were provided to participants. It was requested that participants did not use electronic equipment or any other source of consultation. The resolution of issues and referrals was the responsibility of the researchers, who were previously trained during the conception of the study.

Table 1 Table presenting the participants' main demographics data

\begin{tabular}{lllll}
\hline ID & $\begin{array}{l}\text { Age } \\
\text { (years) }\end{array}$ & $\begin{array}{l}\text { Duration of experience } \\
\text { with software } \\
\text { development (months) }\end{array}$ & $\begin{array}{l}\text { Have you developed } \\
\text { software as a member } \\
\text { of a team? }\end{array}$ & $\begin{array}{l}\text { If so, how many members } \\
\text { are on this team } \\
\text { (including you)? }\end{array}$ \\
\hline P01 & 19 & 36 & yes & 05 \\
P02 & 24 & 18 & yes & 03 \\
P03 & 25 & 53 & yes & 06 \\
P04 & 23 & 10 & no & 00 \\
P05 & 22 & 0 & no & 00 \\
P06 & 24 & 4 & yes & 05 \\
P07 & 22 & 24 & yes & 05 \\
P08 & 21 & 12 & yes & 06 \\
P09 & 21 & 29 & yes & 10 \\
P10 & 21 & 24 & yes & 10 \\
P11 & 30 & 120 & yes & 08 \\
P12 & 23 & 52 & yes & 04 \\
P13 & 27 & 116 & yes & 11 \\
P14 & 21 & 26 & yes & 03 \\
\hline
\end{tabular}


Table 2 List of definitions of pairs with their execution order

\begin{tabular}{lll}
\hline Pairs ID & Participants ID & Orders of execution \\
\hline Pa01 & P01 & Type 1/Type 2 \\
& P02 & \\
Pa02 & P03 & Type 2 / Type 1 \\
Pa03 & P05 & \\
& P06 & Type 1 / Type 2 \\
Pa04 & P07 & \\
& P08 & Type 2 / Type 1 \\
Pa05 & P09 & \\
& P10 & Type 1 / Type 2 \\
Pa06 & P11 & \\
Pa07 & P12 & Type 2 / Type 1 \\
& P13 & \\
\hline
\end{tabular}

\subsection{Results}

The data obtained through the forms and submitted to the participants and the researchers' observations were organized into a data matrix to undergo analysis and measurement that were adequate to the systematic and critical process planned for this research. The analysis results are described from the specific research questions. In this validation report, qualitative data will be prioritized.

Considering the "RQ1: would the proposed graphical construction, provided by the compositions of actor's social complexities, allow to elaborate diagrams that could concentrate on a given situation?", the seven pairs participating indicated that compositions of actor's social complexities assisted in reading and understanding the monolithic model of the iStar framework. In activities related to this issue, participants needed to identify actors, their associations, their dependencies and their internal intentional elements, as well as address the lack of hierarchy of the iStar models. The difficulties encountered were problems in visualizing all elements, understanding priorities, organizing more complex models, not being able to highlight the most important or higher priority elements of the model, and lack of reading order (beginning, middle and end). When asked for suggestions to minimize or even eliminate such difficulties, the participants suggested: top-down hierarchical presentation, enumeration of elements (sequencing), and placement of the elements from left to right, going from the highest to the lowest priority (definition of reading flow, for example).

The pairs' opinions were similar: the actor's social complexity assisted in the understanding, while the monolithic model made the process more costly. The following observations were made independently of the order the documentation was executed: the social modeling scenario presented was exposed as a single block, as traditionally is done in the framework, then two compositions of the actor's social complexity were presented, and it was questioned if these compositions appear as modular alternatives to the iStar's monolithic structure. Only one pair $(\mathrm{Pa} 01)$ stated that composition made understanding harder and, thus, the monolithic, which did not present the option of managing the number of elements, made things easier. On the other hand, for the six remaining pairs, 
reducing the amount of information displayed improved the understanding of the featured actor and highlighted the actor's relationships. This is because only the relevant or the desired information for a given situation was presented.

As evidence, the following reports regarding composition can be presented: $\mathrm{Pa} 02$ - "It represents an improvement, because it reduces the data that is necessary at the time, leaving only relevant information"; Pa03 - "It enables a better understanding, because it makes it possible to verify the dependence between this actor and the other actors (traveler/internet) and their reliable independence, in which there is no relationship of dependency on other actors"; Pa04 - "Since it abstracts the other actors focusing only on the essential relationships with the community, it facilitates the understanding because it simplifies reading"; Pa05 - "It enables a better understanding because the actors and all of the relationships that are tied to the community actor is evidenced".

In Table 3, the answers to questions related to the characteristics of SMiLe are summarized. The response instruments offered were based on the Likert scale.

When it comes to "RQ2: would the SMiLe, through its structure and reserved words, help to read and understand the iStar framework model?", the respondents replied that SMiLe assists in reading and understanding the iStar framework model. The pairs considered that SMiLe extends the scope of the iStar model by offering different mental models for the same space provided in two representations: a graphical and a textual one. Even though they can be worked on independently, when it interacts with one another for the single purpose of complementation it enriches the context of observation, understanding, and complexity of the model. When two activities that are exclusively in the SMiLe notation were presented to someone, and they were asked to answer questions on the fulfillment of internal needs and the interests of external relationships on the actor's social complexity, the pairs responded appropriately. It also happened when the actor's description was presented, and it was asked if it would be necessary to know the other actors of the organization to identify the actions and social relations of the actor, as well as how this actor performed a specific task for another actor.

Table 3 Participants' responses to the assessment questions related to the SMiLe characteristics

\begin{tabular}{|c|c|c|c|c|}
\hline Questions & $\begin{array}{l}\text { Completely } \\
\text { disagreed }\end{array}$ & Disagreed & Agreed & Completely agreed \\
\hline $\begin{array}{l}\text { i) The understanding of } \\
\text { independence in the actor's } \\
\text { description is beneficial }\end{array}$ & - & - & $\begin{array}{l}04 \text { pairs (Pa01, } \\
\mathrm{Pa02}, \mathrm{Pa04}, \mathrm{Pa} 05)\end{array}$ & $\begin{array}{l}03 \text { pairs ( } \mathrm{Pa03}, \mathrm{Pa} 06, \\
\mathrm{Pa07})\end{array}$ \\
\hline $\begin{array}{l}\text { ii) SMiLe offers modularity in } \\
\text { the actor's description }\end{array}$ & - & - & $\begin{array}{l}02 \text { pairs ( } \mathrm{Pa} 02, \\
\mathrm{Pa05})\end{array}$ & $\begin{array}{l}05 \text { pairs }(\mathrm{Pa} 01, \mathrm{~Pa} 03, \\
\mathrm{Pa04}, \mathrm{Pa} 06, \mathrm{~Pa} 07)\end{array}$ \\
\hline $\begin{array}{l}\text { iii) It provides a description } \\
\text { pattern }\end{array}$ & 01 pair (Pa07) & - & $\begin{array}{l}03 \text { pairs }(\mathrm{Pa} 01 \\
\mathrm{Pa} 03, \mathrm{~Pa} 05)\end{array}$ & $\begin{array}{l}03 \text { pairs }(\mathrm{Pa} 02, \mathrm{~Pa} 04, \\
\mathrm{Pa06})\end{array}$ \\
\hline iv) It provides a reading pattern & - & - & $\begin{array}{l}02 \text { pairs ( } \mathrm{Pa} 02, \\
\text { Pa05) }\end{array}$ & $\begin{array}{l}05 \text { pairs }(\mathrm{Pa} 01, \mathrm{~Pa} 03, \\
\mathrm{Pa05}, \mathrm{Pa} 06, \mathrm{~Pa} 07)\end{array}$ \\
\hline $\begin{array}{l}\text { v) The fact that building blocks } \\
\text { allow to managing information } \\
\text { from the iStar (monolithic) } \\
\text { model }\end{array}$ & - & - & $\begin{array}{l}05 \text { pairs }(\mathrm{PaO} 1 \\
\mathrm{Pa} 02, \mathrm{~Pa} 05, \mathrm{~Pa} 06, \\
\mathrm{~Pa} 07)\end{array}$ & $\begin{array}{l}02 \text { pairs ( } \mathrm{Pa} 03 \text { and } \\
\mathrm{Pa04})\end{array}$ \\
\hline $\begin{array}{l}\text { vi) The fact that building blocks } \\
\text { allow parallel work to be done }\end{array}$ & - & $\begin{array}{l}02 \text { pairs } \\
(\mathrm{Pa04}, \mathrm{Pa} 05)\end{array}$ & $\begin{array}{l}02 \text { pairs ( } \mathrm{Pa} 01 \\
\mathrm{Pa02} \text { ) }\end{array}$ & $\begin{array}{l}03 \text { pairs }(\mathrm{Pa} 03, \mathrm{~Pa} 06, \\
\mathrm{Pa07})\end{array}$ \\
\hline $\begin{array}{l}\text { vii) The characteristic of } \\
\text { making it easier to change } \\
\text { from future uncertainties to } \\
\text { the organization }\end{array}$ & 01 pair (Pa01) & - & $\begin{array}{l}02 \text { pairs (Pa02 e } \\
\text { Pa05) }\end{array}$ & $\begin{array}{l}04 \text { pairs }(\mathrm{Pa} 03, \mathrm{~Pa} 04, \\
\mathrm{Pa} 06, \mathrm{~Pa} 07)\end{array}$ \\
\hline
\end{tabular}


Following, evidence found in the pairs' report are exposed: Pa01 - "It makes it easier since textual reading helps to interpret graphical notation, as well as graphical reading helps in the interpretation of a textual notation"; Pa03 - "It facilitates. The graphical model allows to have a better overview of the system, and the textual one allows a better view of the participation of each actor. The complexity is reduced because the textual language allows a better identification of the participation of each actor in the relationships"; Pa04 "Yes, it facilitates the understanding, since what is not completely understood through the diagram may be easier to learn through textual notation, and so is the opposite"; Pa05 - "It makes it easier because it presents two different ways to understand the same problem. It reduces (complexity) because there is a hierarchy between the elements which facilitates the understanding"; Pa07 - "The presence of textual notation makes it easier to understand the diagram because it provides a guide to walk through it. However, it is likely that only the textual notation is already enough".

The results of this validation have provided a broader vision for recognizing the weaknesses that need to be improved and the high spots that should still be strengthened. There was also a reduction in the uncertainty of the participants' acceptance of a hybrid representation for the iStar framework.

\section{Discussions}

At the beginning of the iStar framework's review, considering the iStar framework's attractiveness (rich expressiveness for social modeling and versatility to combine goals and agent-oriented paradigms) and the community's wishes, like working contexts with a large number of elements, tools that offered easy adaptive and corrective maintenance were searched. The use and the analysis of the functionalities of the tools found, such as the correctness of the models generated by them and facilities for modifying the models created led to the understanding that, apparently, these tools had limitations related to attending an analyst's needs. Developing a tool with new directions that would provide a solution that could quickly evolve and adapt was an option based on the research carried out and the experience in development environments. It was also encouraged by the interest of combining new concepts and concepts that are still being consolidated to a non-existent tooling support, as hybrid approach (graphical e textual) and views through compositions of actors' social complexities.

From the literature review that was carried out, new proposals to serve the software development industry were found, such as the approach of a model intermediate to the one that was proposed for services (Esquivel 2008) and for compositions of services, which generated an overload in the learning curve; and (Franch 2010), which, aware of this overload, sought mechanisms that minimized this problem using modules of the concepts of the iStar model and thus began to work with the compositions of modules related to the model itself. Meanwhile, the new version of iStar, version 2.0, adopted an approach in which views became distinct from the iStar model (Dalpiaz et al. 2016). This allowed the proposal presented in this work to delimit an interdependent part based on the actor's social complexity, a term already used in the framework's documentation in the iStarWiki (I* Wiki).

Based on this state of art and technique, and on new concepts not yet contemplated in technical instruments, these were conceived: a modular conceptual model based on the actor's social complexity (part); a social modeling composition (whole) 
based on the set of these complexities; and an architecture for this proposal. The final architecture proposed was composed of three levels of abstraction, with the following artifacts highlighted in each layer: the SMiLe - textual notation, the SMiLeCompiler compiler, and the environments for end users, which help to compose the actor's social complexities.

This proposal for a composition based on the actor's social complexities favors scalability. Considering Lima et al's work (Lima et al. 2016), of the five characteristics that enrich the scalability concept for the iStar framework, it is possible to see that three of them permeate the proposed solution. Namely, they would be: i) to treat and manipulate different size applications the same way - since the social information of the model will be distributed in interdependent parts, manipulation may always be according to the desired parts, regardless of how many parts there are in the whole; ii) to have visions at various levels of abstraction - with the possibility of managing, through the composition mechanism, the visualization of a desired set of actors and their social information, different contexts or sub-contexts can be created; and iii) to be easily modifiable - in a top-down visualization approach, it is possible to understand the interdependent parts from the whole (social model) and thus modify them without the overhead of elements.

The intention has always been to manage graphical complexity through compositions. In this process, the development of a textual notation added new insights to this proposal. Since its creation, the SMiLe has expanded the application of the Dual Coding Theory (Paivio 1991), as well as the provision of an initial structure to assist a modeling tool by separating social information from graphical information. This textual notation offers facilities such as platform integration and independence. With this textual notation and compiler in hand, to verify its robustness and flexibility in different social contexts, the chosen way was to carry out a proof of concept of the proposal and, later, perform the validation with users. Thus, several social models from the SD and SR models were submitted to the SMiLe modeling based on the actor's social complexity. These models submitted underwent an experimental validation, considering real scenarios of use, the modeling's social dynamics and the human understanding of this proposal.

The proposal presented itself, based on the evaluations to which it was submitted theoretical reference, proof of concept and validation, as an alternative to managing the graphical complexity of iStar models. Also, when considering a hybrid approach, SMiLe was configured as an alternative to help understand the graphical models. In the resulting documentation, participants positively highlighted the approach considering it easy to understand and to construct hybrid models (graphical and textual). For the hybrid approach, the way it is being planned through the tooling support: i) from the selection of the target element (intentional element or actor), request the set of social information described in the textual notation. This information requested will be presented in a popup window (similar to the strategy of some integrated development environment (IDE) to present the documentation - ex.: Javadoc, when it comes to classes; or ii) when requested of a particular selected actor, a presentation, side by side, of the two representations (graphic and textual).

Unpretentiously, it is hoped that the interdependent part proposed by the actor's social complexity by SMiLe is configured as an extension point of the iStar framework through textual markings in the modeling, without interfering in the graphic. This will allow the 
composition and reuse of the actor's social complexities. This proposal would increase the framework's abstraction power, which could win new adherents, and further enhance the loyalty of those who are part of their community.

\subsection{Limitations of the proposal and threats to validity}

A limitation of the initial proposal was the fact that the instrumentation implementation was not concluded, thus making the full evaluation impossible. Also, during the design of the architecture, the framework underwent a redesign, which resulted in iStar 2.0 (Dalpiaz et al. 2016), making some propositions not fully aligned. It was also observed that to enhance an adequate human-computer interaction, there is a need to explore more sophisticated mechanisms to manipulate the information intrinsic to the actor's social complexity and their compositions.

Authors such as Engelen and van den Brand (2010), Grönninger et al. (2014), Ottensooser et al. (2012) and Sharafi et al. (2013) verified the lack of significant superiority between language styles (graphic and textual). Even so, it is known that textual notation carries with it the following limitations: i) inability to rearrange elements due to their linear structure; ii) lack of formalism and, consequently, greater difficulty to be interpreted given the inherent characteristics of ambiguity, incompleteness, and redundancy. SMiLe deals with these limitations from its semi-formalism, which does not necessarily guarantee the extinction of the indicated limitations.

Regarding the evaluation of the proposal, the participants were students of the discipline of Requirements Engineering. Although there were some professionals with experience in the area of modeling and software development, the majority had no professional maturity in the area. Also, these can be cited as threats to validity, which could not be circumvented in time: mortality and compensation. To mitigate these threats, one can visualize, in a moment not too distant, an evaluation of the proposal in the iStar community.

\section{Works related}

For this proposal, the social modeling is performed through the composition of interdependent blocks, since this construction is directly related to the concept of modularity and, consequently, scalability of the iStar framework (Esquivel 2008; Franch 2010). To deal with the social complexity absorbed by the iStar models, a concept that could be an interdependent part of social modeling with well-defined inputs and outputs was explored within the iStar models themselves. Moreover, they are allowed to be read, interpreted and understood isolated from the other parts, as it happens in process-oriented models through their subprocesses.

When the study was carried out, the interdependent part was designed from the iStar models proposed in the framework, without resulting in new graphical elements or incorporating concepts that could associate learning overloads, such as the aspect (Alencar et al. 2008; Alencar et al. 2010) and service (Esquivel 2008) approaches. Considering this learning overload and a more significant acceptance from the community, the designated path was simplicity, which was aligned with the following proposals: the inclusion of modules for the construction of models through the composition of these modules (Franch 2010), as well as the revision of the iStar framework, which causes the distinction between the iStar model and the views (Dalpiaz et al. 2016). 
Esquivel's proposal (Esquivel 2008) brought an intermediate model, which was preponderant to the generation of service-oriented iStar models. This very much resembles the intention of this work in separating social information from the organization of graphic information. This social information (intermediate model) was structured to enhance human understanding. Moreover, unlike the concept overload imposed by the serviceoriented approach, this work sought, within the framework's own elements, a conceptual abstraction for the interdependent part.

As proposed by Franch (2010), a model composed of parts was defined in this research. However, in this work, the primary requirement for designing the smallest unit of social information was to be self-contained. The purpose of this was to develop a unit with the least possible loss of understanding related to the context in which it would be inserted.

Despite understanding the scope of this work, the objective was to compose iStar models using interdependent parts. This was presented as the cornerstone to providing new paths in the quest for complexity reduction. Therefore, improvements in the fundamentals of, for example, models modularity and visualization and understanding of models by users can be considered as indirect consequences. Besides these works, there are other researches such as those carried out by Silva et al. (2016), Horkoff and Yu (2010) and Ernest et al. (2006), which address this problem from Shneiderman's visual information seeking mantra - "overview first, zoom and filter, then details-on-demand" (Shneiderman 1996). Thus, even though this proposal was conducted by an interdependent part of the models, there are some consequences related to the mantra.

In Silva et al. (2016), there is a three-way proposal (big picture, syntax-based view and concern-based view) to provide interactive mechanisms that allow users to analyze pieces of information. Although the major objective was common, the way to achieve this graphic reduction was different from the form considered in this paper (composition of social complexities). But even so, the composition of the actor's social complexities conceived by stakeholders can take into account the same interactive mechanisms mentioned above.

Different from this proposal and Silva et al's work (Silva et al. 2016), the works Horkoff and Yu (2010) and Ernest et al. (2006) does not reduce the number of elements and the complexity of the iStar models, which was conceptualized in this paper. This happens due to the inability to offer the possibility of hiding graphic elements, which are not part of the desired context. The routing of the solutions proposed by Horkoff and Yu (2010) and Ernest et al. (2006) have brought a more significant cognitive and learning load to the iStar framework since they have brought new elements.

\section{Conclusion}

As a starting point, it was intended to provide an alternative to deal with the complexity of graphical models, when abstracting systems involving large numbers of elements. Thus, this research proposed a social model composed of small units (interdependent parts). This small unit has been conceptualized as the actor's social complexity, in which the unity is the actor's perspective, combining all of its associations with other actors, their dependency relationships, and internal elements. This actor's social complexity is part of 
a social modeling in which the management of different social complexities that compose it is allowed to offer several compositions according to the intention of those stakeholders and visualized in the view of the iStar framework: SD or SR.

Thus, the modularity offered by this proposal should be highlighted for enabling the creation of views through the composition of interdependent blocks, exploring concepts and elements involved in a domain. Considering this proposal, the creation of diagrams can be made in a way that is adequate and natural, similar to the real world. There was a considerable effort from the authors to try to bring together the concepts of modularity, which are present in the context of organizations, using the elements of the iStar model itself to define an interdependent building block. The importance of the definition of blocks is, precisely, to provide a modular representation that allowed the reduction of the models' cognitive load.

In the process of offering support to the designed proposal, an alternative representation channel was designed to improve understanding of the iStar framework models. This channel takes the textual route and is complementary to the iStar graphic models. Thus, another result was the creation of a reading pattern for the iStar models closest to the natural human language. This reading pattern provides the user with the generation of (co)relationships which have made the understanding, use, and modeling of contexts of interest easier. Meanwhile, the architecture proposal for this hybrid approach, the SMiLe, made the proposed approach more robust and flexible to user demands and contexts of use.

This proposal's differential lays on the search for the conceptual minimalism, in the definition of the smaller comprehensible and interdependent module for the language, and in the use of textual notation as an instrument for the iStar framework's social modeling, which favors human understanding. Thus, the explicit contributions offered were: (i) an interdependent part (actor's social complexity); (ii) a general architecture for the proposal; (iii) the instrumentalization of the proposal through SMiLe and SMiLeCompiler; as well as (iv) the use of a hybrid approach (textual and graphical) to strengthen the social modeling understanding.

As for future work, the following are imminent: (i) the creation of a Web environment to provide collaborative analysis and sharing of iStar models with the goals of identifying patterns, reusing social knowledge, and formalizing patterns, for example; (ii) the implementation of a tool for the construction, consultation and reviews of iStar models and the SMiLe modular textual notation, which could allow the expansion of the facilities of the intrinsically hybrid approach; (iii) evaluation of this proposal and the artifacts produced by the industry.

\footnotetext{
Abbreviations

Language SMiLeQL: SMiLe query language; P: Participant; Pa: Pair; RQ: Research question; SD: Strategic dependency; SMiLe: Scalable modular iStar language; SMiLeCompiler: Compiler for scalable modular iStar; SR: Strategic rationale; TFIC:
} Term of free and informed consent; TIAVU: Term of image, audio and video use; UML: Unified modeling language

\section{Acknowledgements}

The authors are grateful for the support of all of the participants, and the students of the disciplines offered by the Software Testing and Specifications Laboratory of the Federal University of Rio Grande do Norte (LETS/UFRN). The present paper is an extended and reviewed version of a previous work published at the XX Workshop on Requirements Engineering (WER17) entitled "Uma Notação Textual Modular e Escalável para Modelos de Requisitos iStar" (Penha et al. 2017). The authors also thank JSERD editors for this invitation.

Funding

The research was not funded by any organization. 
Availability of data and materials

Data will be available on request.

\section{Authors' contributions}

The first author (FP) contributed to conceptualization, data curation, formal analysis, investigation, resources, software, validation, writing, review and editing of the manuscript. The second author (EM) contributed to conceptualization, data curation, formal analysis, investigation, methodology, resources, validation, writing, review and editing of the manuscript. The third author (ML) contributed to methodology, project administration, resources, supervision, review and editing of the manuscript. The fourth author (LL) contributed to review and editing of the manuscript. The fifth author (FA) contributed to project administration, supervision, review and editing of the manuscript. The sixth author (CA) contributed to to review and editing of the manuscript. All authors read and approved the final manuscript.

\section{Authors' information}

Fábio Fernandes Penha is a doctoral candidate in the Department of Informatics and Applied Mathematics from Federal University of Rio Grande do Norte - UFRN, and Professor at Federal Institute of Rio Grande do Norte (IFRN) since March 2012. His main research interests in Computer Science concern model based engineering requirement, programming languages, software engineering and their applications to the design of software systems. Contact him at fabio.penha@ifrn.edu.br.

Erica Esteves Cunha de Miranda is a Ph.D. candidate in Computer Science at the Federal University of Rio Grande do Norte (UFRN), and she is a M.Sc. in Informatic from the Federal University of Rio de Janeiro (UFRJ). Her main research interests is in Software Engineering, and key topics are Requirements Engineering, Software Development Processes, Agile Ecosystems, Artefacts Traceability, Legal Requirements and Legal Compliance. Contact her at eecmiranda@gmail.com. Marcia Jacyntha Nunes Rodrigues Lucena is an Associate Professor at the Federal University of Rio Grande do Norte (UFRN), working in the areas of Database, Software Engineering and Applied Informatics to Education. She received her PhD degree in Software Engineering at UFPE (2010). She holds a degree in Computer Science from the Federal University of Rio Grande do Norte (1992) and a Master's Degree in Computer Science from the Federal University of Pernambuco (1996). She is permanent member in the Post-graduate program in Systems and Computing at UFRN. Her main interests are in Requirements Engineering, Requirements-Oriented Requirements Models, Legal Requirements, Requirements Traceability, Agile Processes, Software Development Processes and Educational Games. Contact her at marciaj@dimap.ufrn.br.

Leonardo Reis Lucena is an Associate Professor at the Federal Institute of Rio Grande do Norte (IFRN). He holds a degree in Electrical Engineering from the Federal University of Rio Grande do Norte (1993) and a Master's Degree in Computer Science from the Federal University of Pernambuco (1999). He has experience in computer science, with emphasis on Programming Languages, acting on the following topics: design and implementation of programming languages, domain-specific languages and functional languages. Contact him at leonardo.lucena@ifrn.edu.br.

Fernanda Maria Ribeiro de Alencar is a Full Professor of the Federal University of Pernambuco (UFPE) - Graduate degree in Electrical/Electronic Engineering (1986) at UFPE, MS degree in Electrical Engineering (1991) at UFPE and PhD degree in Computer Science (1999) at UFPE; Post-Doctorate at the New University of Lisbon (UNL), Portugal (2006) and Post-Doctorate at the Polytechnic University of Valencia (UVP), Spain (2008-2009). Leader of the Group on Requirements Engineering, Network and Computational Intelligence (GRENCI) and founding member and active participant of the Research Laboratory of Requirements Engineering (LER), both of UFPE, and a member of the Software Engineering Group of the University of Pernambuco (UPE). Permanent member of the Post-Graduate Program in Computational Engineering (PPGEC) at Poli/UPE and collaborating member of the Post-Graduation Program in Electrical Engineering (PPGEE) at UFPE. Her research interests are in Requirements Engineering, Agent-Oriented Development, Aspect-Oriented Development, Operational Systems, Active Methodologies, Embedded Systems and Internet of Things (IoT). Contact her at fmra@ufpe.br. Celso Luiz Agra de Sá Filho holds a Graduate degree in Computer Science at Catholic University of Pernambuco (2011) and a Master's Degree in Computer Science from the University of Pernambuco (2015). He has expertise in Computer Science, with emphasis on systems development. Contact him at celso.agra@gmail.com.

\section{Competing interests}

The authors declare that they have no competing interests.

\section{Publisher's Note}

Springer Nature remains neutral with regard to jurisdictional claims in published maps and institutional affiliations.

\section{Author details}

${ }^{1}$ Federal Institute of Education, Science and Technology of Rio Grande do Norte (IFRN), 59015-300 Natal, Brazil. ${ }^{2}$ Department of Informatics and Applied Mathematics (DIMAp), Federal University of Rio Grande do Norte (UFRN), 59078-970 Natal, Brazil. ${ }^{3}$ Informatic Center (CIn), Federal University of Pernambuco (UFPE), 50740-560, Recife, Brazil.

Received: 17 May 2018 Accepted: 30 August 2018

Published online: 20 September 2018

\section{References}

Alencar F, Castro J, Moreira A, Araújo J, Silva C, Ramos R, Mylopoulos J (2008) Integration of Aspects with i* Models(Kolp M, Henderson-Sellers B, Mouratidis H, Garcia A, Ghose AK, Bresciani P, eds.), Vol. 4898. Springer, Berlin. https://doi.org/ 10.1007/978-3-540-77990-2_11

Annosi MC, De Pascale A, Gross D, Eric SK (2008) Analyzing software process alignment with organizational business strategies using an agent-and goal-oriented analysis technique-an experience report. In: Proceedings of the 3rd International i* Workshop. iStar'08. CEUR Workshop Proceedings. CEUR-WS.org, Recife Vol. 322. pp 9-12. ISSN: 1613-0073 
Alencar F, Castro J, Lucena M, Santos E, Silva C, Araújo J, Moreira A (2010) Towards modular i* models. In: Proceedings of the 2010 ACM Symposium on Applied Computing. SAC'10. ACM, New York. pp 292-297. https://doi.org/10.1145/ 1774088.1774150

Abdelzad V, Amyot D, Alwidian SA, Lethbridge T (2015) A textual syntax with tool support for the goal-oriented requirement language. In: Proceedings of the Eighth International i* Workshop. iStar 2015. CEUR Workshop Proceedings. CEUR-WS.org, Ottawa Vol. 1402. pp 61-66. ISSN: 1613-0073

Baldwin CY, Clark KB (2003) Managing in an age of modularity. Manag Modular Age: Architectures Netw Organ 149:84-93

Baldwin CY, Clark KB (2006) Modularity in the design of complex engineering systems(Braha D, Minai A, Bar-Yam Y, eds.). Springer, Berlin. https://doi.org/10.1007/3-540-32834-3_9

Bryman A (2006) Integrating quantitative and qualitative research: how is it done? Qual Res 6(1):97-113

Barjis J (2008) The importance of business process modeling in software systems design. Sci Comput Program 71(1):73-87

Boucher Q, Classen A, Faber P, Heymans P (2010) Introducing tvl, a text-based feature modelling language. In: Proceedings of the Fourth International Workshop on Variability Modelling of Software-intensive Systems, VaMoS'10, Linz. pp 27-29

Bello O, Zeadally S (2013) Intelligent device-to-device communication in the internet of things. IEEE Syst J 10(3):1172-1182

Creswell J (2009) Research Design: Qualitative, Quantitative, and Mixed Methods Approaches. SAGE Publications, Incorporated, USA

Carvallo JP, Franch X (2009) On the use of $i^{*}$ for architecting hybrid systems: A method and an evaluation report. In: Persson A, Stirna J (eds). The Practice of Enterprise Modeling. PoEM 2009. Lecture Notes in Business Information Processing. Springer, Berlin Vol. 39. pp 38-53. https://doi.org/10.1007/978-3-642-05352-8_5

Classen A, Boucher Q, Heymans P (2011) A text-based approach to feature modelling: Syntax and semantics of tvl. Sci Comput Program 76(12):1130-1143

Cavalcanti PDL (2015) Mapeamento sistemático sobre escalabilidade do i* (istar). Master's thesis, FCT-UNL, Recife, Pernabumco

Dalpiaz F, Franch X, Horkoff J (2016) istar 2.0 language guide. arXiv preprint. http://arxiv.org/abs/1605.07767. Accessed 23 May 2018

Ernst N, Yu Y, Mylopoulos J (2006) Visualizing non-functional requirements. In: Proceedings of the First International Workshop on Requirements Engineering Visualization. REV'06. IEEE, Minneapolis. pp 2-2. https://doi.org/10.1109/REV. 2006.10

Engelen L, van den Brand M (2010) Integrating textual and graphical modelling languages. Electron Notes Theor Comput Sci 253(7):105-120

Esquivel HE (2008) A service-oriented approach for the $\mathrm{i}$ * framework. PhD thesis, Valencia University of Technolog

Franch X (2010) Incorporating Modules into the i* Framework. In: Pernici B (ed). Advanced Information Systems Engineering. CAiSE 2010. Lecture Notes in Computer Science. Springer, Berlin Vol. 6051. pp 439-454. https://doi.org/ 10.1007/978-3-642-13094-6_34

Franch, X (2012) The i* framework: The way ahead. In: Proceedings of the Sixth International Conference on Research Challenges in Information Science. RCIS 2012. IEEE, Valencia. pp 1-3. https://doi.org/10.1109/RCIS.2012.6240418

Genon N, Heymans P, Amyot D (2011) Analysing the cognitive effectiveness of the BPMN 2.0 visual notation. In: Malloy B, Staab S, van den Brand M (eds). Software Language Engineering. SLE 2010. Lecture Notes in Computer Science. Springer, Berlin Vol. 6563. pp 377-396. https://doi.org/10.1007/978-3-642-19440-5_25

Gubbi J, Buyya R, Marusic S, Palaniswami M (2013) Internet of things (iot): A vision, architectural elements, and future directions. Futur Gener Comput Syst 29(7):1645-1660

Grönninger H, Krahn H, Rumpe B, Schindler M, Völkel S (2014) Textbased modeling. arXiv preprint. https://arxiv.org/abs/ 1409.6623. Accessed 23 May 2018

Gonçalves E, Castro J, Araújo J, Heineck T (2018) A systematic literature review of istar extensions. J Syst Softw 137:1-33

Horkoff J, Yu E (2010) Visualizations to support interactive goal model analysis. In: Proceedings of the Fifth International Workshop on Requirements Engineering Visualization. REV 2010, Sydney. pp 1-10. https://doi.org/10.1109/REV.2010. 5625664

I* Wiki. http://istar.rwth-aachen.de/tiki-index.php?page=iStar+2.0+Core+Language. Accessed 23 May 2018

Langlois RN (2002) Modularity in technology and organization. J Econ Behav Organ 49(1):19-37

Lucena M, Castro J, Silva C, Alencar F, Santos E (2011) Stream: a strategy for transition between requirements models and architectural models. In: Proceedings of the 2011 ACM Symposium on Applied Computing. SAC '11. ACM, New York. pp 699-704. https://doi.org/10.1145/1982185.1982337

Lima P, Vilela J, Goncalves E, Pimentel J, Holanda A, Castro J, Alencar F, Lencastre M (2016) Scalability of iStar: a Systematic Mapping Study. Wer 45:289-302

Mazanec M, Macek O (2012) On general-purpose textual modeling languages. In: Proceedings of the 2012 Workshop Databases, texts, specifications, and objects. DATESO 2012. CEUR Workshop Proceedings. CEUR-WS.org, Zernov Vol. 12. pp 1-12. ISSN: 1613-0073

Medeiros ADC (2017) Smilecompiler: Um analisador sintatico e semaantico para notacao textual de modelos istar. Graduação em engenharia de software - tcc, Natal

Nunes CM (2009) Uma linguagem de domínio específico para a framework i. Master's thesis. FCT-UNL

Ottensooser A, Fekete A, Reijers HA, Mendling J, Menictas C (2012) Making sense of business process descriptions: An experimental comparison of graphical and textual notations. J Syst Softw 85(3):596-606

Parnas DL (1972) On the criteria to be used in decomposing systems into modules. Commun ACM 15(12):1053-1058

Paivio A (1991) Dual coding theory: Retrospect and current status. Can J Psychol 45(3):255-287

Petre M (1995) Why looking isn't always seeing: readership skills and graphical programming. Commun ACM 38(6):33-44

Penha F, Lucena M, Lucena L, Alencar F, Sá Filho C (2017) Uma notação Textual Modular Escalável para Modelos de Requisitos IStar. Paper presented at the 20th Workshop on Requirements Engineering - WER, Pontificia Universidad Católica Argentina, Buenos Aires, May 22-23, 2017. In: Proceedings of the XX Iberoamerican Conference on Software Engineering. ClbSE 2017. Curran Associates, Buenos Aires. pp 347-360. ISBN 978-99967-839-2-0 
Reijers H, Mendling J (2008) Modularity in process models: Review and effects. In: Dumas M, Reichert M, Shan MC (eds). Business Process Management. BPM 2008. Lecture Notes in Computer Science. Springer, Berlin Vol. 5240. pp 20-35. https://doi.org/10.1007/978-3-540-85758-7_5

Shneiderman B (1996) The eyes have it: a task by data type taxonomy for information visualizations. In: Proceedings of the 1996 IEEE Symposium on Visual Languages. VL 1996. IEEE, Boulder. pp 336-343. https://doi.org/10.1109/VL.1996. 545307

Sweller J, Van Merrienboer JJ, Paas FG (1998) Cognitive architecture and instructional design. Educ Psychol Rev 10(3):251-296

Sommerville I (2010) Software Engineering. 9th. Addison-Wesley Publishing Company, USA

Sharafi Z, Marchetto A, Susi A, Antoniol G, Guéhéneuc Y (2013) An empirical study on the efficiency of graphical vs. textual representations in requirements comprehension. In: Proceedings of the 21st International Conference on Program Comprehension. ICPC 2013. IEEE, San Francisco. pp 33-42. https://doi.org/10.1109/ICPC.2013.6613831

Silva L, Moreira A, Araújo J, Gralha C, Goulão M, Amaral V (2016) Exploring views for goal-oriented requirements comprehension. In: Comyn-Wattiau I, Tanaka K, Song IY, Yamamoto S, Saeki M (eds). Conceptual modeling. ER 2016 Lecture Notes in Computer Science. Springer, Cham Vol. 9974. pp 149-163. https://doi.org/10.1007/978-3-31946397-1_12

Yu ES-K (1996) Modelling strategic relationships for process reengineering. PhD thesis, Toronto, Ont., Canada, Canada. UMI Order No. GAXNN-02887 (Canadian dissertation)

Yu ES (2009) Social modeling and $i^{*}$. Lecture Notes in Computer Science (including subseries Lecture Notes). Artif Intell Lect Notes Bioinforma 5600 LNCS(c):99-121

Yu E (2011) Modelling strategic relationships for process reengineering. Soc Model Requir Eng 11:2011

Zhi J, Ruhe G (2013) Devis: A tool for visualizing software document evolution. In: Proceedings of the First IEEE Working Conference on Software Visualization. VISSOFT 2013. IEEE, Eindhoven. pp 1-4. https://doi.org/10.1109/VISSOFT.2013. 6650526

\section{Submit your manuscript to a SpringerOpen ${ }^{\odot}$} journal and benefit from:

- Convenient online submission

Rigorous peer review

Open access: articles freely available online

- High visibility within the field

- Retaining the copyright to your article

Submit your next manuscript at $\boldsymbol{\triangleright}$ springeropen.com 